\title{
Artificial Neural Network Prediction of Weld Distortion Rectification using a Travelling Induction Coil
}

\author{
C.J.Barclay ${ }^{1}$, S.W.Campbell ${ }^{1}$, A.M.Galloway ${ }^{1}$, N.A.McPherson ${ }^{2}$ \\ ${ }^{1}$ Department of Mechanical \& Aerospace Engineering, University of Strathclyde, Glasgow, Scotland \\ ${ }^{2}$ BAE Systems Maritime - Naval Ships, 1048 Govan Road, Glasgow, Scotland
}

\begin{abstract}
An experimental investigation has been carried out to determine the applicability of an induction heating process with a travelling induction coil for the rectification of angular welding distortion. The results obtained from experimentation have been used to create artificial neural network models with the ability to predict the welding induced distortion and the distortion rectification achieved using a travelling induction coil.
\end{abstract}

The experimental results have shown the ability to reduce the angular distortion for $8 \mathrm{~mm}$ and 10 $\mathrm{mm}$ thick DH36 steel plate and effectively eliminate the distortion on $6 \mathrm{~mm}$ thick plate. Results for 6 $\mathrm{mm}$ plate also show the existence of a critical induction coil travel speed at which maximum corrective bending occurs.

Artificial neural networks have demonstrated the ability to predict the final distortion of the plate after both welding and induction heating. The models have also been used as a tool to determine the optimum speed to minimise the resulting distortion of steel plate after being subjected to both welding and induction heating processes.

\section{Introduction}

Fusion welding is one of the most commonly used joining processes in the metal fabrication industry and is essential for the development of many manufactured products [1]. It is well known [2-6] that the welding process introduces residual stresses to the structure as a result of the non-uniform expansion and contraction of the weld metal and consequently results in distortion in the final structure [3-6]. Distortion can be classified into categories of in-plane and out-of-plane distortion, within which there are a number of modes of distortion [3] each of which can significantly affect the accuracy of fit up for the structure [7].

Many structures are constructed using an assembly process, and consequently distortion can be detrimental when the welded sub-structures have to be aligned and joined together. For example, fillet welds are commonly used in the shipbuilding industry to attach stiffener bars to larger flat sections to improve the rigidity of the structure (Figure 1). However, as observed in Figure 1, fillet welded configurations generally lead to out-of-plane angular distortion along with transverse and longitudinal shrinkage, with out-of-plane distortion being particularly troublesome when joining the previously mentioned flat sections to one another to form part of a larger structure $[2,4]$. 


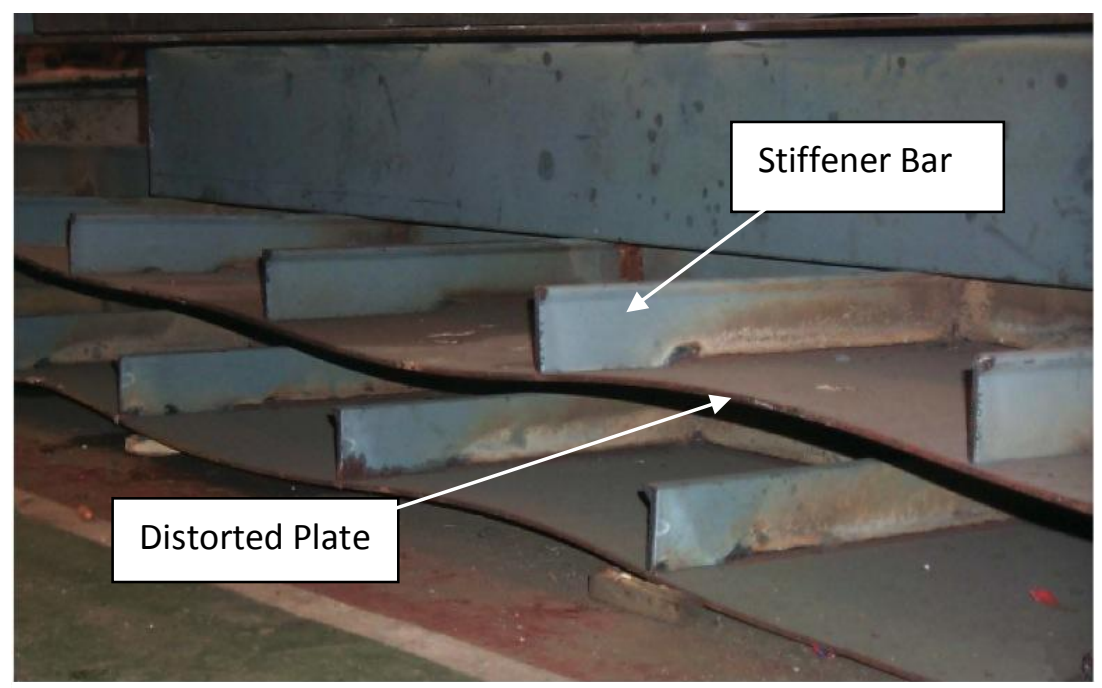

Figure 1 - Example of distorted steel plate with welded stiffeners

The dominant mode of out-of-plane distortion produced when welding in the fillet weld configuration is angular distortion due to transverse shrinkage of the weld metal during solidification $[4,5]$. It is known that the magnitude of distortion is affected by a number of factors including the shielding gas flow rate, weld geometry, plate thickness and welding speed [8-11]. In particular welding speed has been shown to have a significant impact on distortion as it is one of the primary parameters of controlling heat input during welding [9]. Computational modelling methods such as Finite Element Analysis and Artificial Neural Networks have previously been implemented to predict the out-of-plane distortion experienced by a structure due to the welding process and have shown the ability to predict the final distortion with a reasonable degree of accuracy $[4,12]$.

Traditionally, flame straightening and mechanical straightening have been used to reduce distortion in welded structures to within tolerance. Flame straightening relies on localised expansioncontraction effects due to the heating-cooling cycle to generate bending within the structure. The process is dependent on the thermal contraction of the material, during the cooling phase, inducing tensile residual stresses within the structure. As a result of the constraints imposed by the unheated surrounding material, this tensile stress generates bending of the plate. The magnitude of bending is controlled by the depth of heat penetration through the plate; insufficient heat input levels do not generate the required contraction on the heated surface, whilst excessive heat input levels result in through thickness heating which generate tensile stresses on the opposite side with an overall reduction in distortion rectification due to inadequate bending. Hence, there is an optimum level of heat input, with the results obtained from flame straightening heavily dependent on the skill of the operator which in turn limits the consistency and repeatability of the process [6]. Consequently, the process is difficult to control when the plate thicknesses is less than $6 \mathrm{~mm}$ [2] as there is a tendency for the applied heat to rapidly penetrate through the entire plate.

Mechanical straightening can be used to rectify distortion by the application of a force to cause plastic deformation of the work piece. This is typically achieved by inserting the weldment into a press or using a series of hydraulic jacks to apply a force and is therefore limited by the size of the press and the geometry of the component that requires rectification. Further, it is has been reported [13] that additional residual stresses will be produced within the material when using this method, which has the potential to cause problems later in the assembly process. 
Induction heating has been used for a number of years for the correction of plate distortion, and has been shown to have a number of advantages over using flame straightening, including improved repeatability, increased productivity and the potential for process optimisation $[6,14]$. The induction heating process uses a coil that, when supplied with a high frequency current, induces eddy currents within the work piece and the electrical resistance of the material causes heat to be generated within the area where the eddy currents form $[15,16]$. As a result of the heating within this area, localised thermal expansion occurs. The material surrounding the heated zone is effectively at ambient temperature, as the rapid rate of heating does not allow sufficient time for heat to be conducted to the surrounding material. Due to the positive coefficient of thermal expansion, and the localised increase in temperature, the heated zone will naturally expand to maintain equilibrium. However, an in-plane constraint is applied to the heated zone as a result of the surrounding material so in order to alleviate some of the thermal stresses, the material expands plastically out-of-plane. Upon removal of the heat source, the large concentration of heat within the heated zone is conducted away and the material within this region contracts while the surrounding material expands as heat is transferred. As the material cools, the region where out-of-plane expansion occurred will reach thermal equilibrium with the surrounding material and the remaining cooling will take place by convection. At this point, the material will undergo almost uniform thermal contraction, however, the region where the heat was applied has already produced in a net in-plane contraction. If the region where the eddy currents generate heat does not penetrate through the entire thickness of the plate then the overall contraction will not be uniform through the thickness of the plate. As a result of this, a residual stress field will be set up, creating tensile stresses within the heated zone and compressive stresses on the opposite side of the plate to balance these. The combination of these stresses results in bending and a permanent deformation of the plate [17]. Figure 2 illustrates this process.

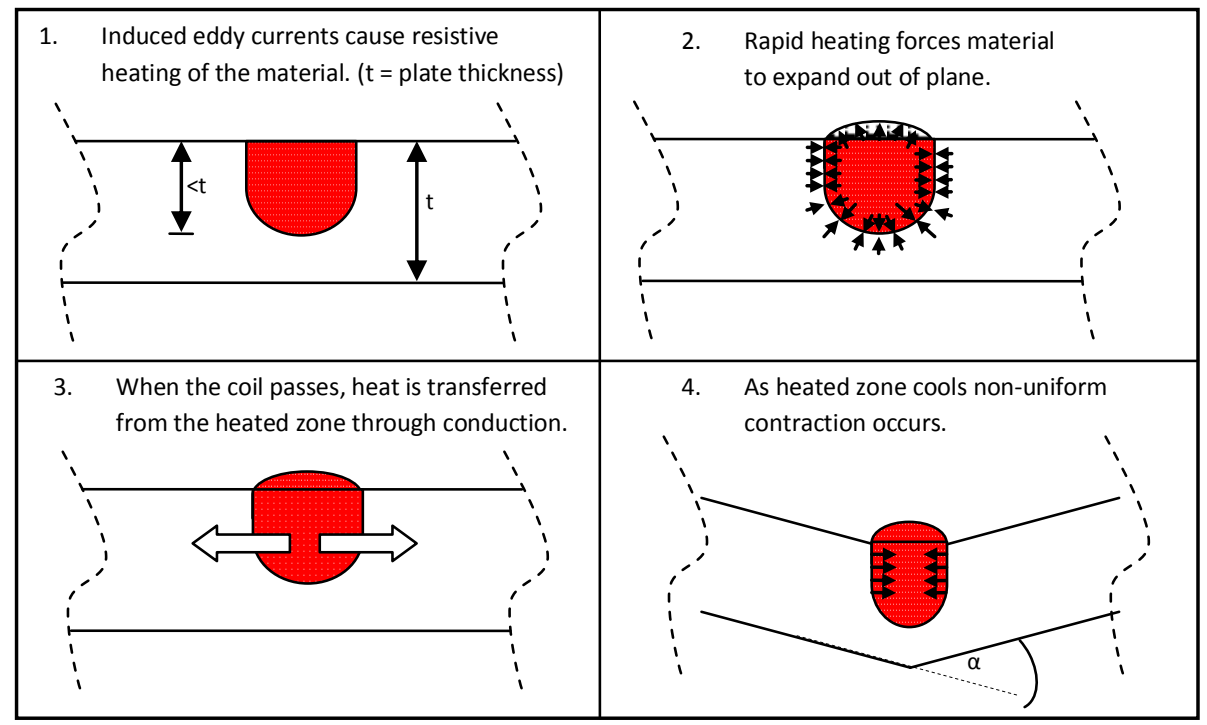

Figure 2 - Diagram of Induction Heating Process Operation 
The conventional method of induction heating involves using a stationary induction coil to strategically heat the plate in a pre-defined pattern to correct the distortion present. This method heats the plate through the entire plate thickness to cause a transverse contraction of the material. For this method to straighten the plate, the edges must be constrained so that the material contraction will result in overall tensile residual stresses in the plate, which will straighten any bends present [14].

More recently, research has shown that a travelling induction coil can also be used to bend steel plate in a forming process $[17,18]$. These studies determined that the bending distortion caused in the process is predictable and, similar to welding, the bending effect is primarily influenced by the travel speed of the coil (the heat input) and the thickness of the plate.

Artificial Neural Networks (ANNs) are computational models that use interconnected layers of processing elements to model and predict relationships between input parameters. The operation of these elements is based upon the operation of neurons within the brain and gives ANNs the ability to cope with relationships that are highly complex and non-linear [19]. When supplied with sufficient training data, ANN models are capable of capturing intricate relationships between parameters and detecting subtle trends that other computational approaches may not. These characteristics make ANN models ideally suited to modelling the welding process with its many closely linked parameters and they have been successfully implemented to predict both weld geometry and welding distortion $[11,12,20]$.

ANN models have also been employed to predict the bending behaviour of steel when subjected to heating with a travelling induction coil [18]. The model produced by Ngyuyen et al. [18] considered the bending produced by induction heating on unwelded steel plates and demonstrated the ability of ANNs to accurately predict the resulting distortion based upon a given set of heating parameters.

This present study aims to generate an ANN model to predict both the resultant transverse angular distortion as a function of the welding parameters, and the transient induction heating parameters required to rectify it. It is proposed that the contraction of the weld material is the major contributing factor to the angular distortion and that heating the side of the plate opposite to the weld bead using induction heating would create an area of contracted material on the opposite side to the weld bead. With regions of thermal shrinkage on both sides of the plate, it is proposed that the level of resulting angular distortion will be forced to decrease and is likely to be eliminated through optimisation of the induction heating parameters. 


\section{Experimental Apparatus/Procedure}

Experimental trials were conducted on $200 \times 1000 \mathrm{~mm}$ DH36 steel plates of various thicknesses (detailed in Table 2) with a $100 \times 1000 \times 8 \mathrm{~mm}$ stiffener welded along the centreline to form an inverted ' $T$ ' fillet weld. The stiffener was tack welded to the base plate with a series of $25 \mathrm{~mm}$ welds, located 160, 330, 500, 670 and $840 \mathrm{~mm}$ along one side of the stiffener.

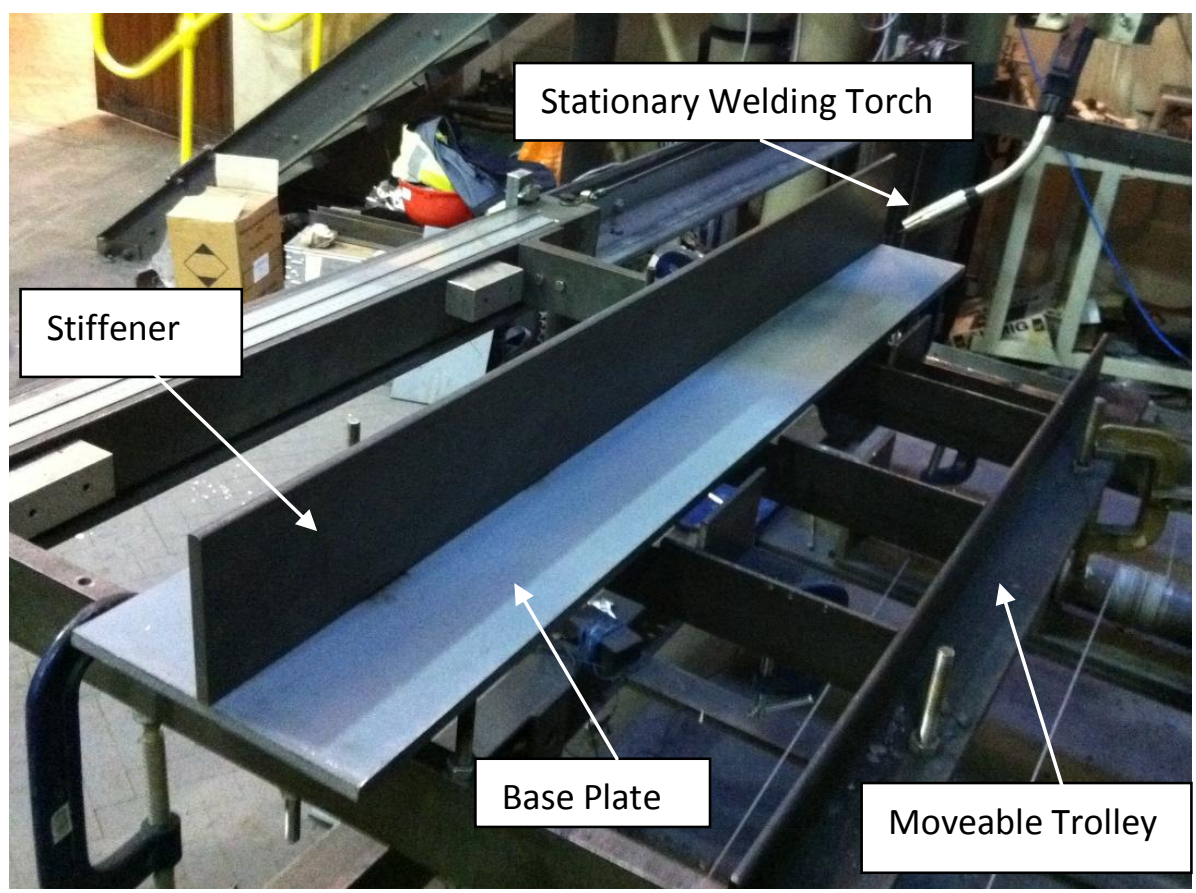

Figure 3 - Experimental plate mounted on welding rig

All experimental welds were performed upon an automatic welding rig (Figure 3), which held the plate rigid upon four locating points, and moved the plates at a pre-set speed beneath a fixed welding nozzle. The rig implemented an optical distance sensor to calibrate the height of each locating point, the sensor was also used to scan the plates according to a pre-defined grid pattern to determine the surface topology of the plate at each stage of the experimental trials; distortion measurements were recorded every $10 \mathrm{~mm}$ in the transverse direction and every $25 \mathrm{~mm}$ in the longitudinal direction. The plates were scanned three times throughout the process: prior to welding (but after the stiffener had been tacked), after welding and after induction heating. In each case, the plates had been allowed to cool to room temperature to ensure no further distortion would occur as no further thermal contraction due to cooling will take place.

Nominal welding parameters were used throughout the experimental trials and the average values were recorded using a portable arc monitoring system. Three different welding travel speeds $(2,2.5$ and $3 \mathrm{~mm} / \mathrm{s}$ ) were used to control the heat input in order to generate different levels of distortion to train the ANN model. Five plates of each thickness were welded at each travel speed. 
An EFD Induction MINAC 18/25 system with a standard $100 \mathrm{~mm}$ induction coil designed for stationary steel plate bending was used during the induction heating phase of the experimental trials. To automate the movement of the induction coil, the hand held terminal (HHT) of the unit was mounted to a GULLCO KAT welding tractor allowing for a consistent travel speed to be pre-set. The coil was positioned at a height $5 \mathrm{~mm}$ from the plate surface, and $9 \mathrm{~mm}$ from the stiffener plate centreline to travel along the opposite side of the plate from the weld, following the centre of the weld heat affected zone. The system was set to produce a constant power output of 19KW, with five different travel speeds being used to produce different levels of bending. The plate and travel speed combinations are given in Table 2 . The experimental set up for the induction heating is shown in Figure 4.

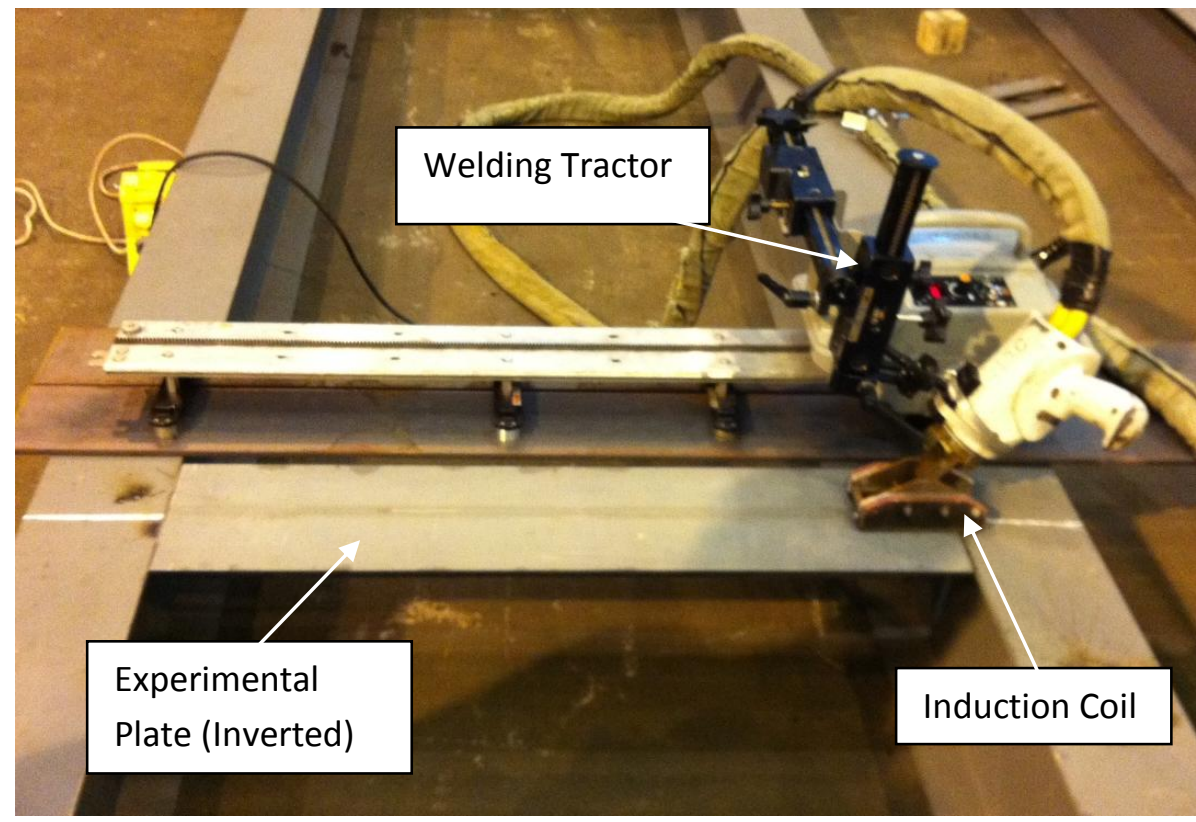

Figure 4 - Experimental Set Up for Induction Heating

\section{Experimental Results}

After each distortion measurement stage, a dataset containing the height of each plate at each of the pre-defined grid points was obtained. To eliminate the effect of any small difference in the height of the 4 mounting points occurring between each stage of experimentation, the mean height of the plate was subtracted from the measurements to produce an array containing the difference in height at each point from the mean height of the plate. These datasets were then used as the base from which the angular (or out-of-plane) distortion was calculated. The distortion of each plate due to welding was obtained by subtracting the dataset obtained before welding from the dataset obtained after, producing an array containing the vertical movement of the plate at each point due to the welding process. The surface plot shown in Figure 5 is an example of the vertical displacement data showing a very distinct $\mathrm{V}$-shape, characteristic of angular distortion, along the entire length of the plate. 


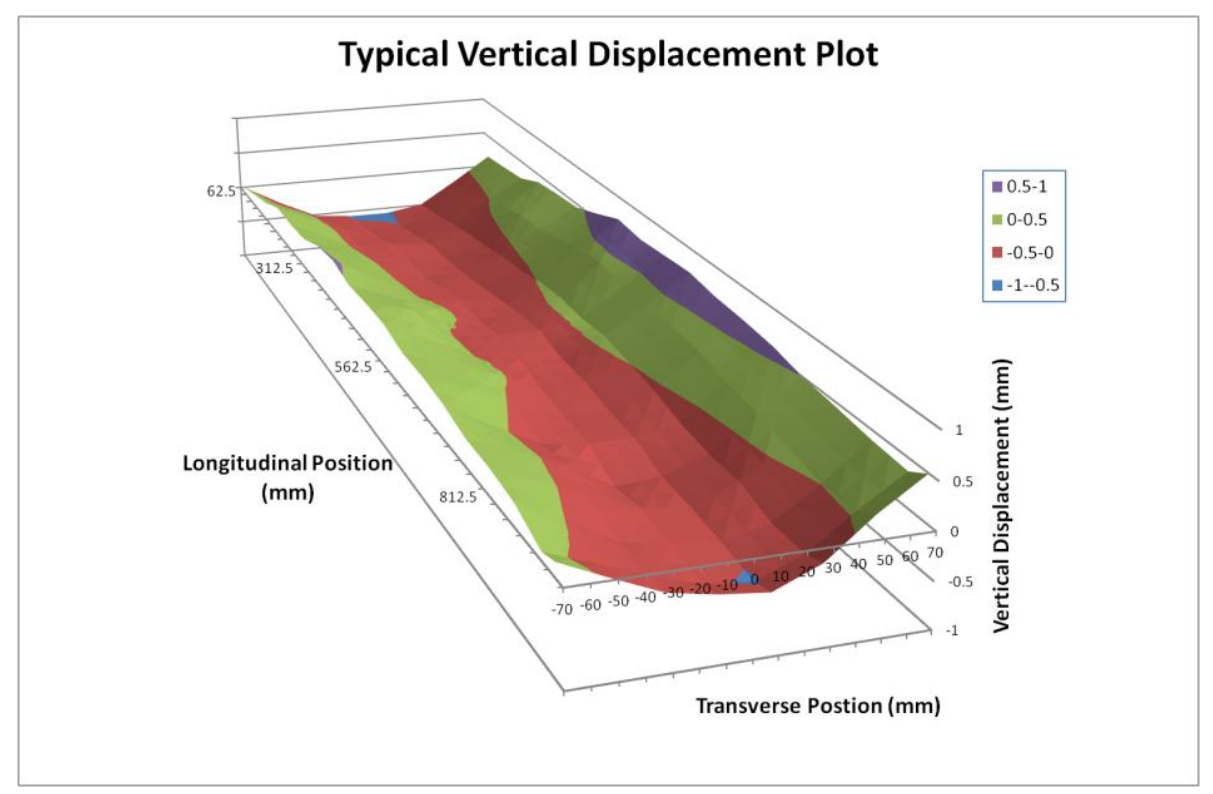

Figure 5 - Vertical Displacement Plot

To quantify the distortion, the mean movement of the plate at each transverse measurement point was determined and plotted against the transverse location from the centreline. The 3 rows in the array containing the data at the centreline and points $+/-10 \mathrm{~mm}$ from the centreline were ignored as these measurements were in the location of the stiffener, experimental weld and tack welds. A best fit straight line was the applied to the data points producing a plot representing the relative angle of each side of the plate as shown in Figure 6. Using the gradients of each line, the resulting angular distortion of the plate was calculated. The final distortion of the plate, after the induction heating process was completed, was calculated in a similar manner by subtracting the pre weld data from the data collected after induction heating. Finally, the rectification due to induction heating was determined by subtracting the post weld and post induction heating angular distortion values.

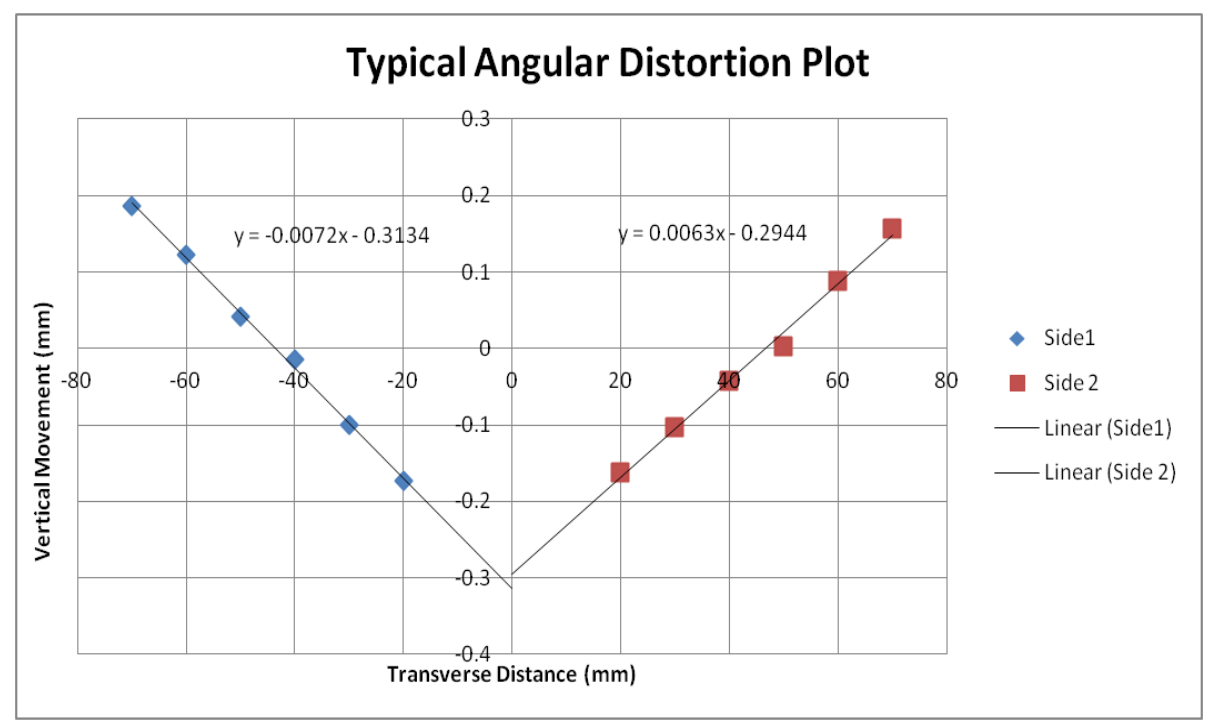

Figure 6 - Angular Distortion Data (Axes not to scale) 


\subsection{Welding Distortion}

The results for angular distortion due to welding for the $6 \mathrm{~mm}$ thick plate samples (Figure 7) display an unusual pattern; the lowest level of distortion is observed on the plates welded at $2 \mathrm{~mm} / \mathrm{s}$ with the greatest observed on the plates welded at $3 \mathrm{~mm} / \mathrm{s}$. This is in contrast to the expected pattern of distortion, which has been shown to decrease with a reduction in heat input [11]. However, it is proposed that the low welding speeds used, which were intended to generate high heat input levels and large levels of distortion, may have caused this unexpected pattern. While welding the $6 \mathrm{~mm}$ samples, the heated zone was clearly visible on the underside of the plate. Hence, the intentionally high heat input level resulted in a significant rise in temperature through the thickness of the plate. This has reduced the temperature difference between the weld and base material, and subsequently, the difference in thermal contraction resulted in lower levels of angular distortion.

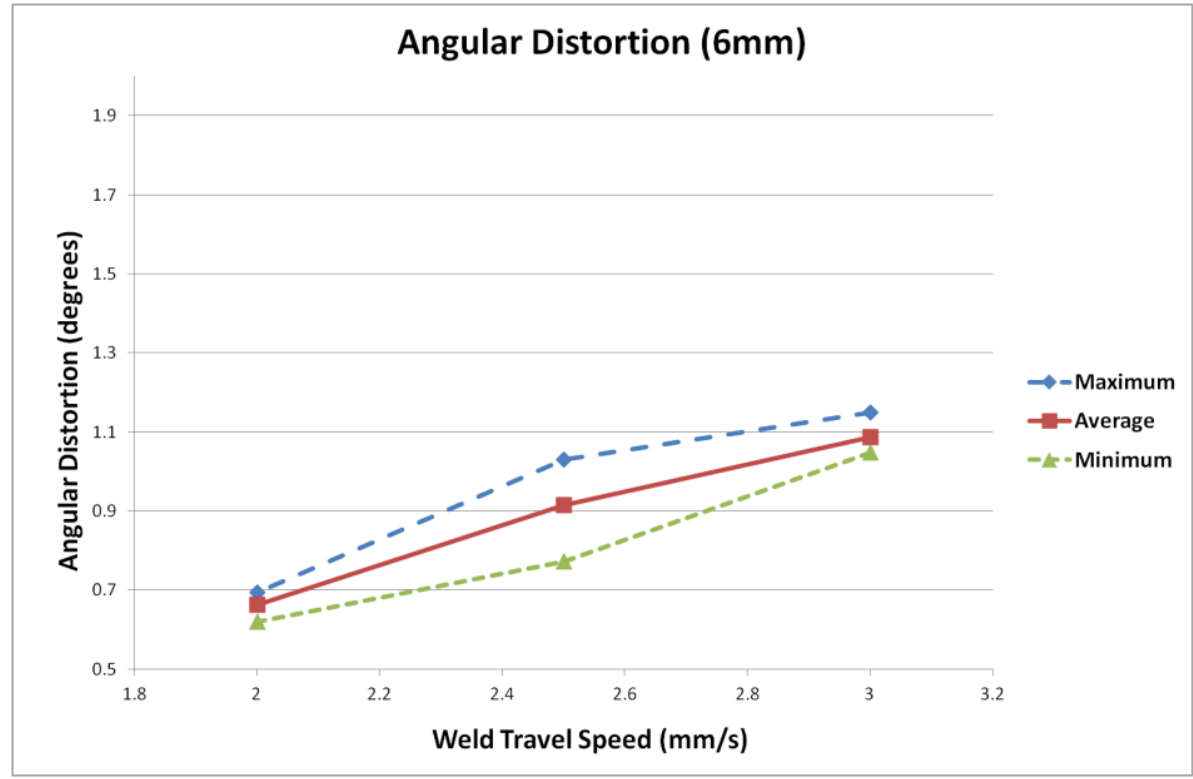

Figure 7-6 mm Plate Welding Distortion

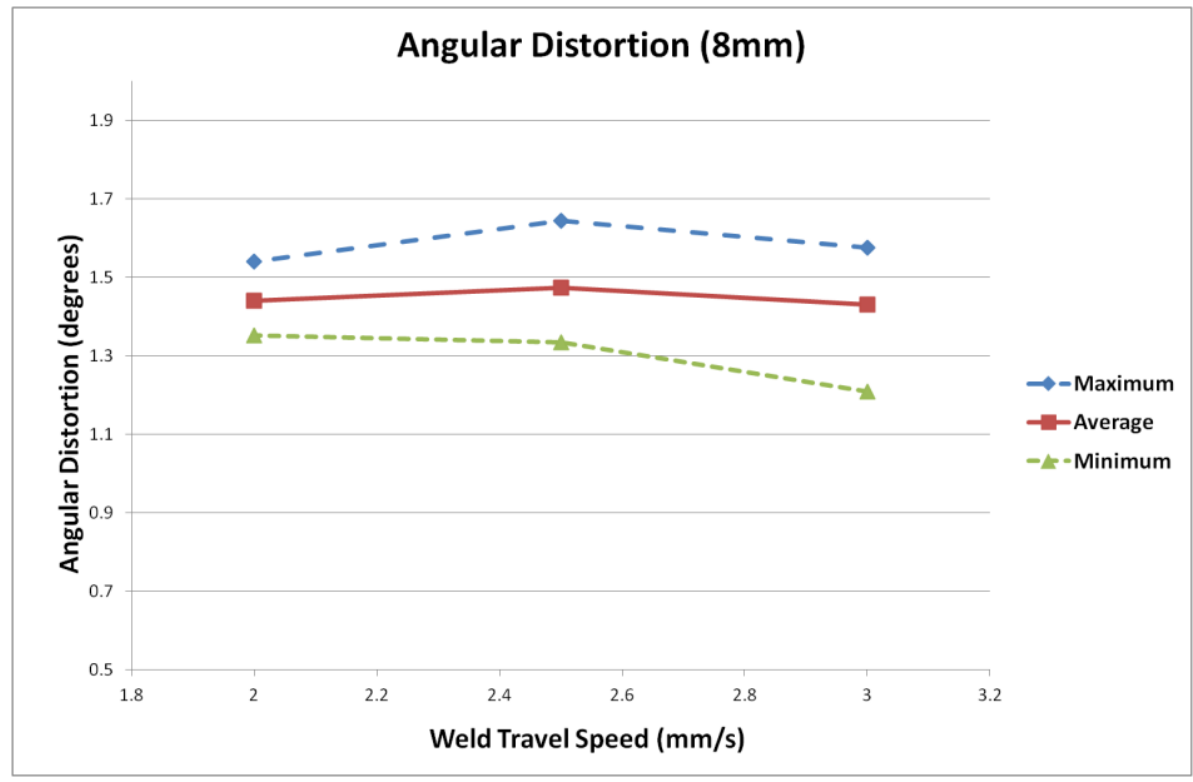

Figure 8-8 mm Plate Welding Distortion 
A different trend is seen in the distortion results for the $8 \mathrm{~mm}$ thick plate samples as illustrated in Figure 8. The level of angular distortion appears to be almost constant with welding speed and overall is significantly greater than the distortion seen on the $6 \mathrm{~mm}$ thick samples with the distortion in the range of $1.209^{\circ}-1.644^{\circ}$ for $8 \mathrm{~mm}$ and $0.63^{\circ}-1.15^{\circ}$ for $6 \mathrm{~mm}$.

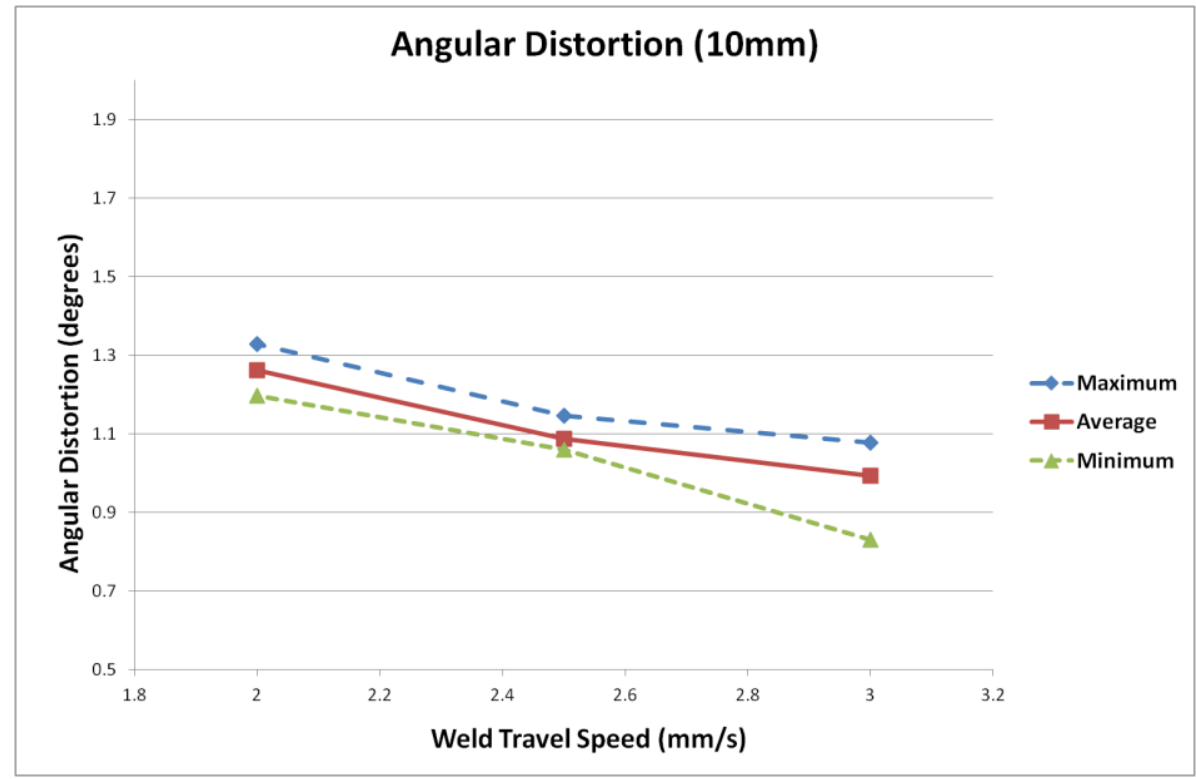

Figure 9-10 mm Plate Welding Distortion

The angular distortion results for the $10 \mathrm{~mm}$ thick samples exhibit the expected trend of distortion (Figure 9), i.e. increasing as weld travel speed decreases. Overall the level of distortion is lower than that found for $8 \mathrm{~mm}$ thick samples, with the $10 \mathrm{~mm}$ thick plate samples showing distortion in the range $0.831^{\circ}-1.329^{\circ}$. This follows the expected pattern of distortion decreasing with increased plate thickness. As discussed previously, this is most likely to be a result of the temperature gradient through the thickness of the plate. As a result of the thinner plates being heated too far through their thickness, in-plane tensile stresses would be produced on the underside of the plate, thus counteracting those on the welded side.

\section{$\underline{3.2 \text { Induction Heating }}$}

To compare the results of the induction heating, the final value of angular distortion has been subtracted from the post weld value producing an angle representing the distortion rectification achieved using the induction heating process. Figure 10 shows the distortion rectification achieved at various induction coil travel speeds on $6 \mathrm{~mm}$ plate and highlights an evident increase in the level of rectification achieved as travel speed is decreased from $30 \mathrm{~mm} / \mathrm{s}$ to $15 \mathrm{~mm} / \mathrm{s}$ with a significant decrease observed when the travel speed is decreased further to $10 \mathrm{~mm} / \mathrm{s}$. This trend is similar to the trend seen in welding distortion with an increase in heat input, due to reduced travel speed, resulting in a reduction in the rectification bend. 
This leads to the hypothesis that a critical coil travel speed exists, where bending increases with reduction in travel speed until this critical speed and thereafter, a further reduction in travel speed causes the rectification to reduce. As previously conversed, this is a result of the heat penetrating too far through the plate. For the $6 \mathrm{~mm}$ plate, the induction heating process was capable of almost eliminating the post weld distortion as the maximum rectification observed was $0.956^{\circ}$ while the maximum welding distortion at this thickness was $1.1^{\circ}$. These results indicate that, with optimised induction heating parameters, it may be possible to completely rectify welding distortion in the 6 $\mathrm{mm}$ plate for the welding parameters used in this study.

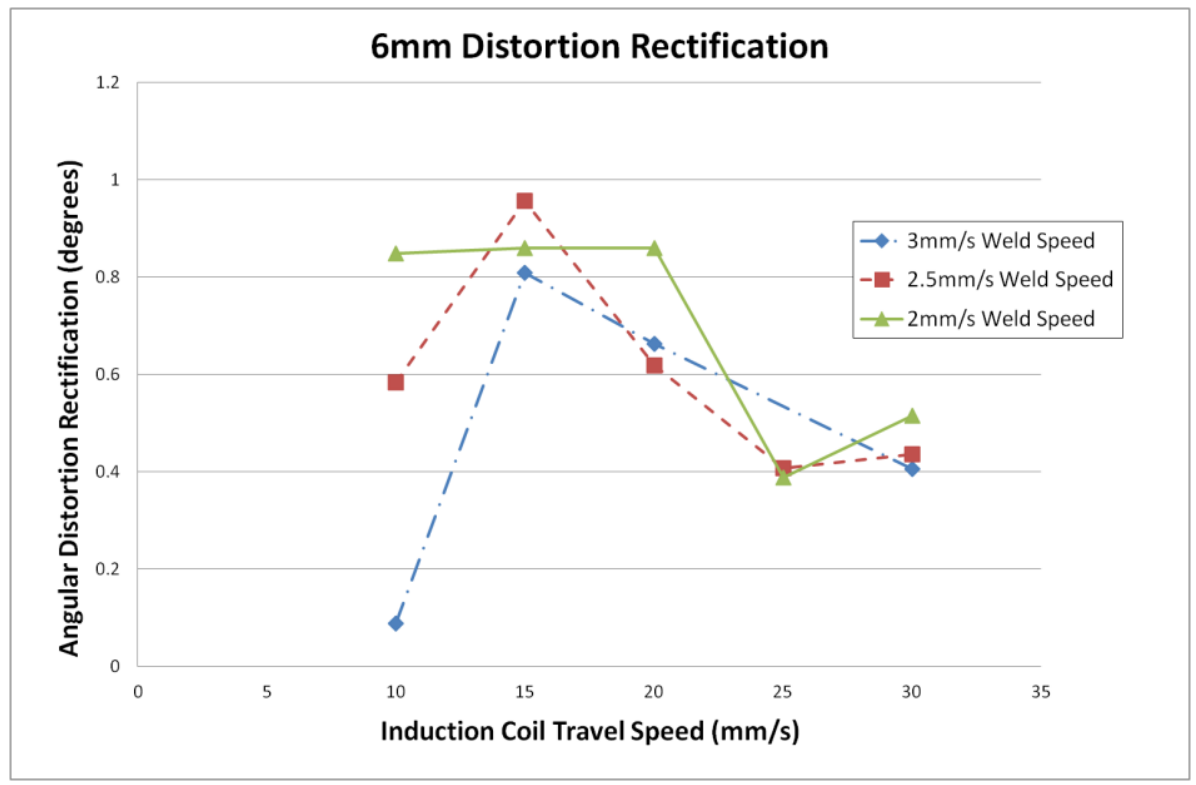

Figure 10-6 mm Distortion Rectification

In the results for the $8 \mathrm{~mm}$ thick samples, the peak rectification that occurred around $15 \mathrm{~mm} / \mathrm{s}$ as seen in the $6 \mathrm{~mm}$ results is not evident. There is an overall trend of increasing rectification with reducing travel speed although there is an anomalous value at $25 \mathrm{~mm} / \mathrm{s}$ within the $3 \mathrm{~mm} / \mathrm{s}$ weld speed data set. The overall maximum rectification value of $0.681^{\circ}$ is lower than that of the $6 \mathrm{~mm}$ results $\left(0.956^{\circ}\right)$ with the increase in plate thickness, and consequently greater stiffness, being the reason for this. In the results displayed in Figure 11, there does not appear to be a critical speed at which maximum rectification bending occurs, however, this critical speed may be in the region of 10 $\mathrm{mm} / \mathrm{s}$ or lower. The parameters used for the induction heating process dictated that a coil travel speed of $10 \mathrm{~mm} / \mathrm{s}$ was the minimum speed used, as trials at $5 \mathrm{~mm} / \mathrm{s}$ resulted in the surface of the heated zone beginning to liquefy due to the extreme level of heat input. At this thickness of plate, the induction heating process is capable of reducing the welding distortion but not eliminating it completely as the maximum measured welding distortion was $1.664^{\circ}$ while the maximum distortion observed was only $0.681^{\circ}$. 


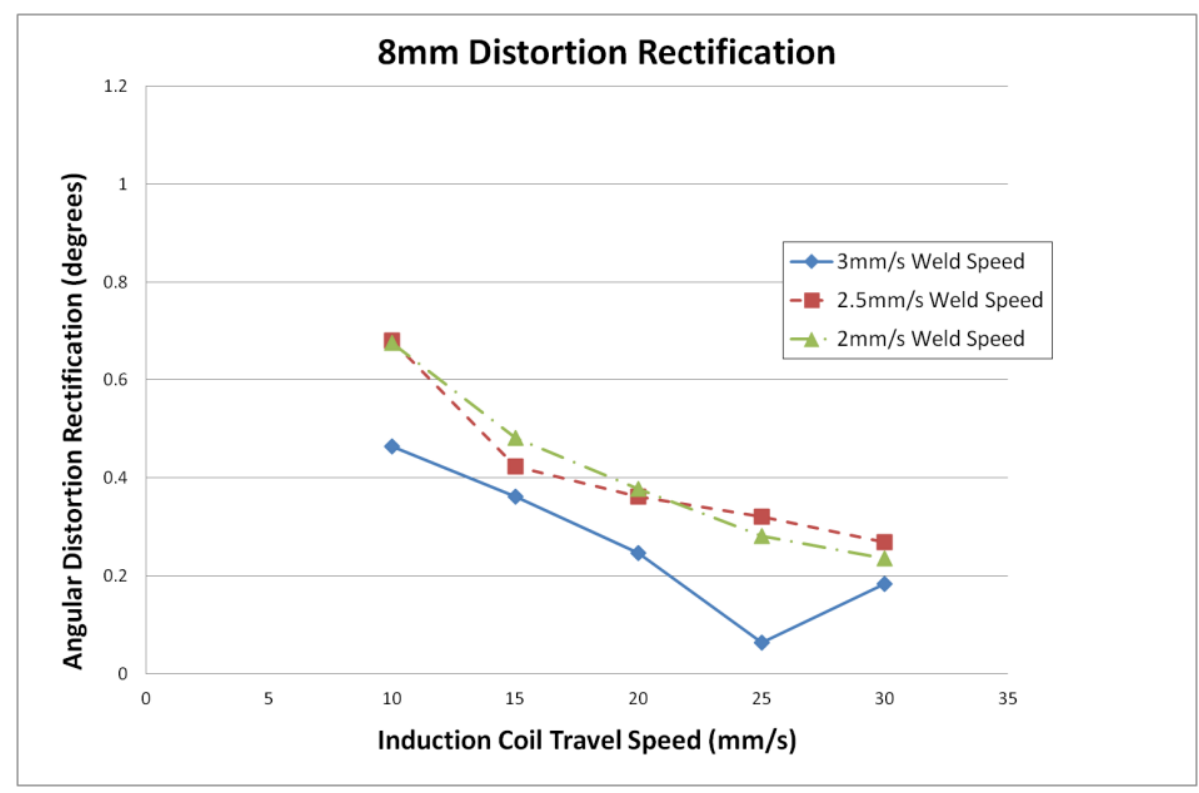

Figure 11 - 8 mm Distortion Rectification

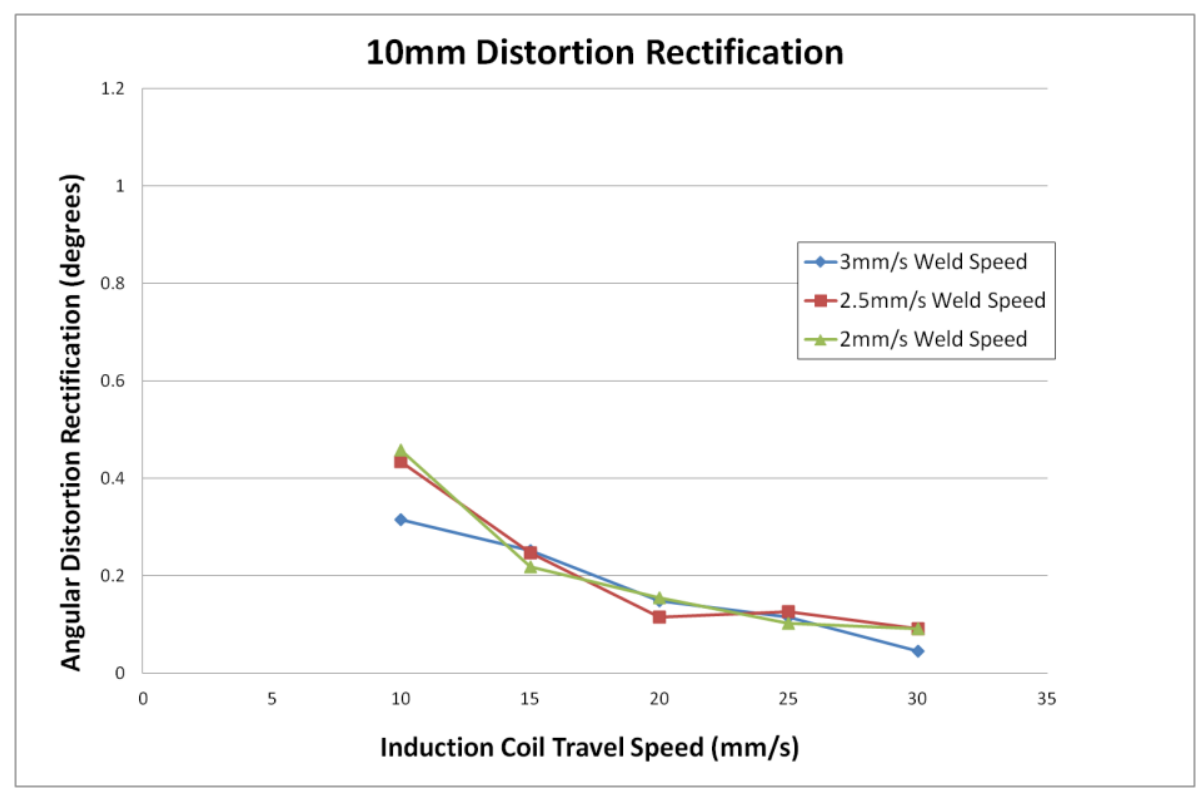

Figure 12-10 mm Distortion Rectification

The results obtained for $10 \mathrm{~mm}$ thick plate (Figure 12) exhibit similar trends to the $8 \mathrm{~mm}$ thick plate with rectification reducing as coil speed increases. The results also reinforce the trend of the maximum rectification reducing as plate thickness increases with a maximum rectification of $0.458^{\circ}$, the lowest of the rectification results for the 3 plate thicknesses. Again the induction heating process has not been capable of eliminating welding distortion as the maximum rectification observed was $0.458^{\circ}$ while the maximum distortion was $1.329^{\circ}$. 
From the results there is a clear relationship between the travel speed of the induction coil and the rectification that can be achieved using this process. As the coil speed is reduced below the critical value, the coil begins to heat the plate through the entire thickness limiting the non-uniform thermal contraction and hence reducing the bending caused by the process. The increasing plate thickness limits the maximum bending that will occur through a combination of increased plate stiffness and an increase in the conductive heat transfer. This increase in conductive heat transfer limits the concentrated build up of heat in the region of the coil and hence reducing the out-of-plane expansion of the material and therefore, the non-uniform thermal contraction upon cooling. These factors lead to the conclusion that this process may be best suited to rectifying distortion in thin plate material.

\section{ANN Model Development}

The model architecture chosen to predict both welding distortion and distortion rectification was multilayer perceptron. This architecture has been previously used successfully in simulations predicting both welding distortion and weld geometry $[11,12,20]$. The development of the model to predict the distortion rectification due to the travelling induction coil was carried out in 3 distinct stages. To determine the most suitable model parameters the following process was used in each stage:

1. The rows of data in Table 2 were randomized with 2 rows chosen at random for crossvalidation of the model and 4 rows chosen for testing. All other rows were used as training data.

2. The topology of the model was systematically varied between 1-3 hidden layers and 2-12 processing elements per layer. Each topology was trained and tested 10 times and the error recorded. The average error of each topology was compared to determine the model topology producing the most accurate results.

3. The learning parameters of the model were then varied in the same manner as before to determine the values that produced the model with the lowest error. The number of training iterations was varied between 2000 and 20000, the momentum coefficient varied between 0.1 and 1 and step sizes of $0.1,0.5$ and 1 tested. The parameters resulting in the lowest error during testing were selected for the final model.

Firstly, a model was constructed using the Neurosolutions software package to predict the resulting welding distortion using the welding parameters and plate thickness as inputs. This model was used to ascertain the ability of the ANN model to predict the pattern of welding distortion. The inputs used for this model were base plate thickness, welding speed, welding voltage and current and the desired output was the post welding angular distortion. Using the model development process defined previously, the parameters for this model were defined as: 
Hidden Layers: 2

Processing Elements Layer 1: 2

Processing Elements Layer 2: 2

Momentum Coefficient: $\quad 0.7$

Step Size: $\quad 0.1$

Iterations: 10000

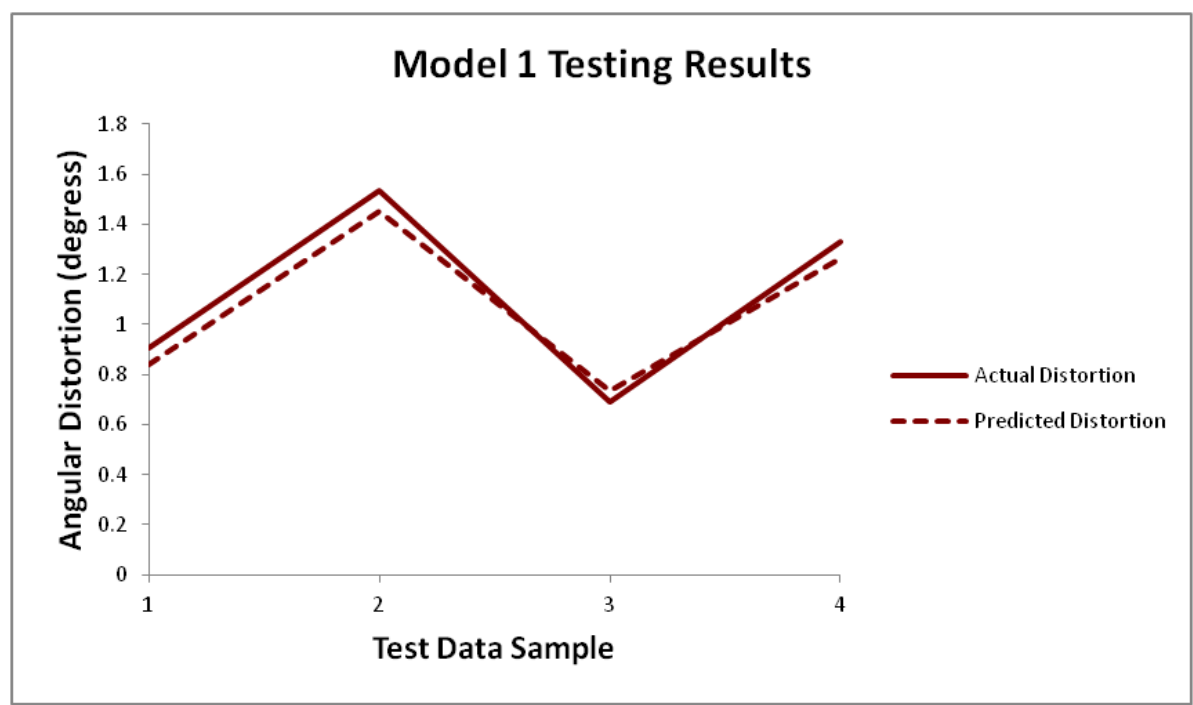

Figure 13 - Welding Prediction Test Data (Model 1)

The range of absolute error for this model during testing was $0.0469^{\circ}-0.0859^{\circ}$ with an average percentage error of $0.0651^{\circ}$. This indicates that an ANN model can predict the angular distortion from the welding parameters and plate thickness with a reasonable degree of accuracy. The results obtained from testing are shown in Figure 13.

A sensitivity study was carried out to determine the effect of each input on the distortion of the plate. To determine the sensitivity of the output against each input variable was varied above and below the mean values and the outputs given by the prediction model were recorded. Each output dataset is then compared to determine the relative sensitivity of the output for each input. Carrying out a sensitivity study is an effective way to understand the influential factors in the modelling process as well as the physical processes of welding an induction heating. Sensitivity studies have previously been used to determine the most influential factors on weld geometry and distortion [11, 20]. In Figure 14, it is clear that, for the experimental welds carried out in this study, plate thickness is the most dominant parameter affecting distortion while weld travel speed also has a small but visible influence. 


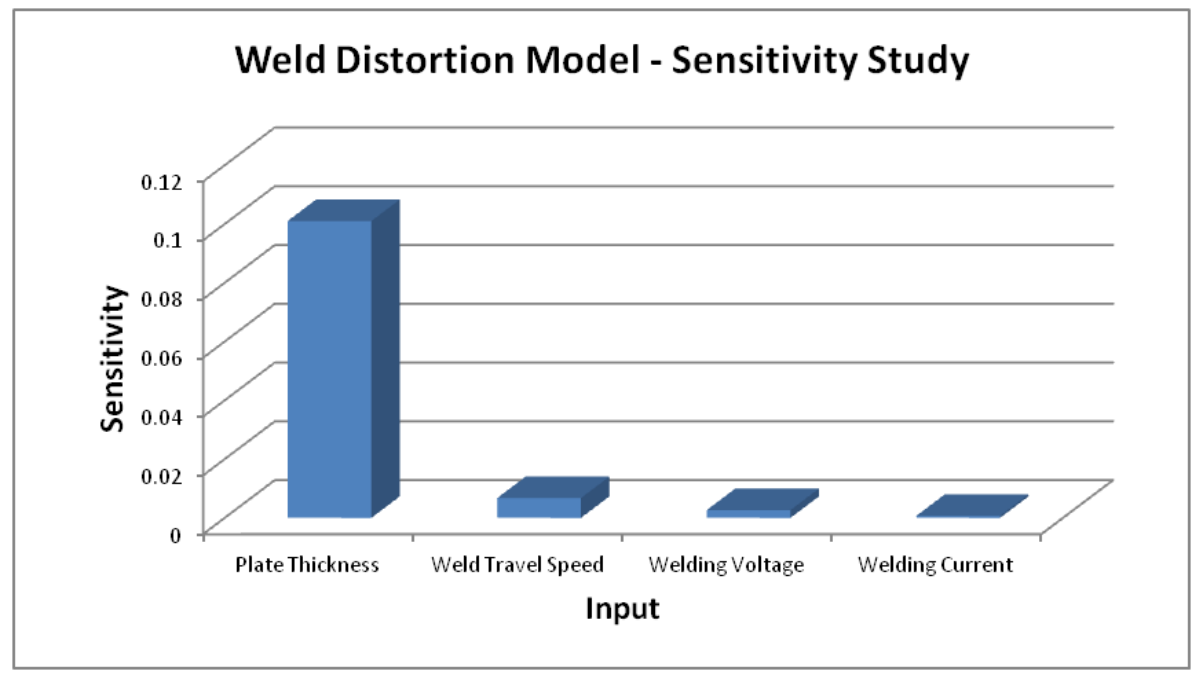

Figure 14 - Weld Distortion Sensitivity Study (Model 1)

The next stage involved the generation of an ANN model to predict the final resulting distortion of the plate after being subjected to both welding and induction heating processes. The aim of this stage was to determine the ability of a model to predict the effect of the travelling induction coil on the angular distortion of the plate. The inputs in this case were the welding parameters, plate thickness, induction coil travel speed and post welding angular distortion. The measured post weld distortion has been selected as an input for this model to allow the model to predict only the effect of the induction heating process on the resulting distortion of the plate. As the power output of the induction coil was constant for all experiments this has not been included as an input. The same model development procedure was used for this model and the final parameters are given below:

Hidden Layers:

2

Processing Elements Layer 1: 12

Processing Elements Layer 2: 5

Momentum Coefficient: $\quad 0.7$

Step Size: $\quad 0.1$

Iterations: $\quad 14000$

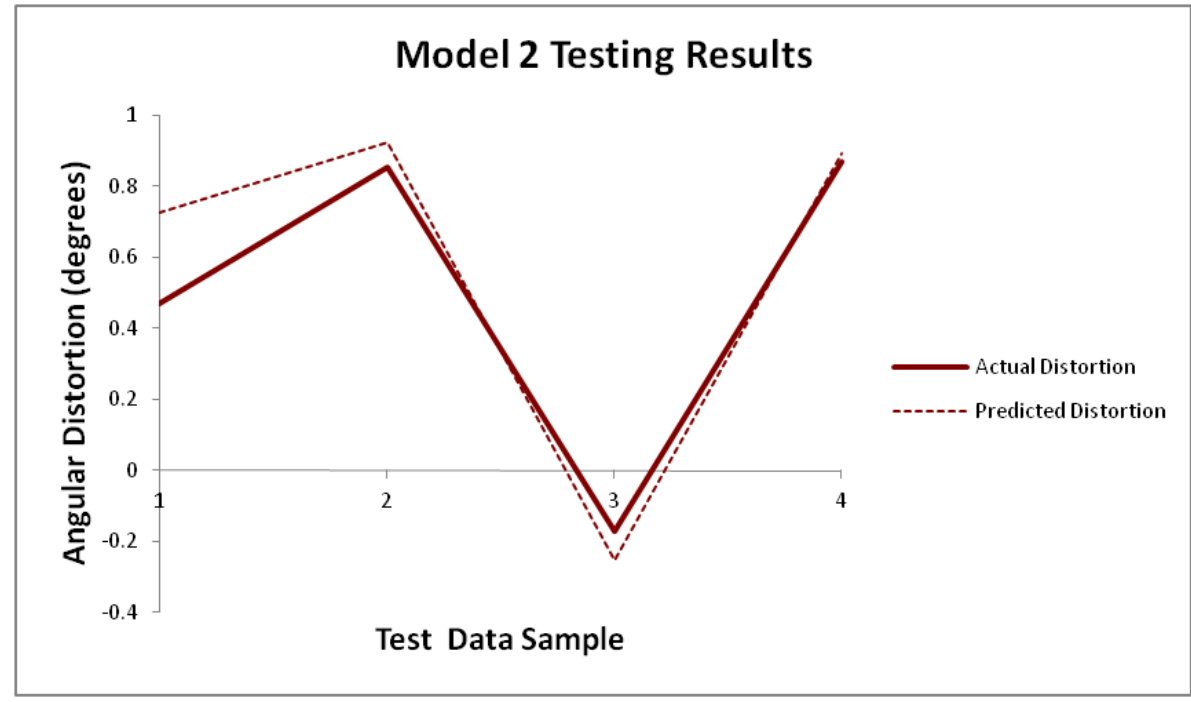

Figure 15- Distortion Rectification Prediction Test Data (Model 2) 
Due to the increased number of inputs, and hence the higher complexity of the relationships between the inputs and output, this model has required more complex topography with 12 processing elements in the first hidden layer and 5 in the second. Overall this model appears to have predicted the distortion for the testing data successfully. A relatively large error of $0.257^{\circ}$ is present in the prediction of the first test sample with the others ranging between $0.022^{\circ}$ and $0.082^{\circ}$ with a mean overall error $0.107^{\circ}$. The testing results for this model are shown in Figure 15 . This mean absolute error is larger than in the first model but this is likely due to the more complex relationships between the inputs and output.

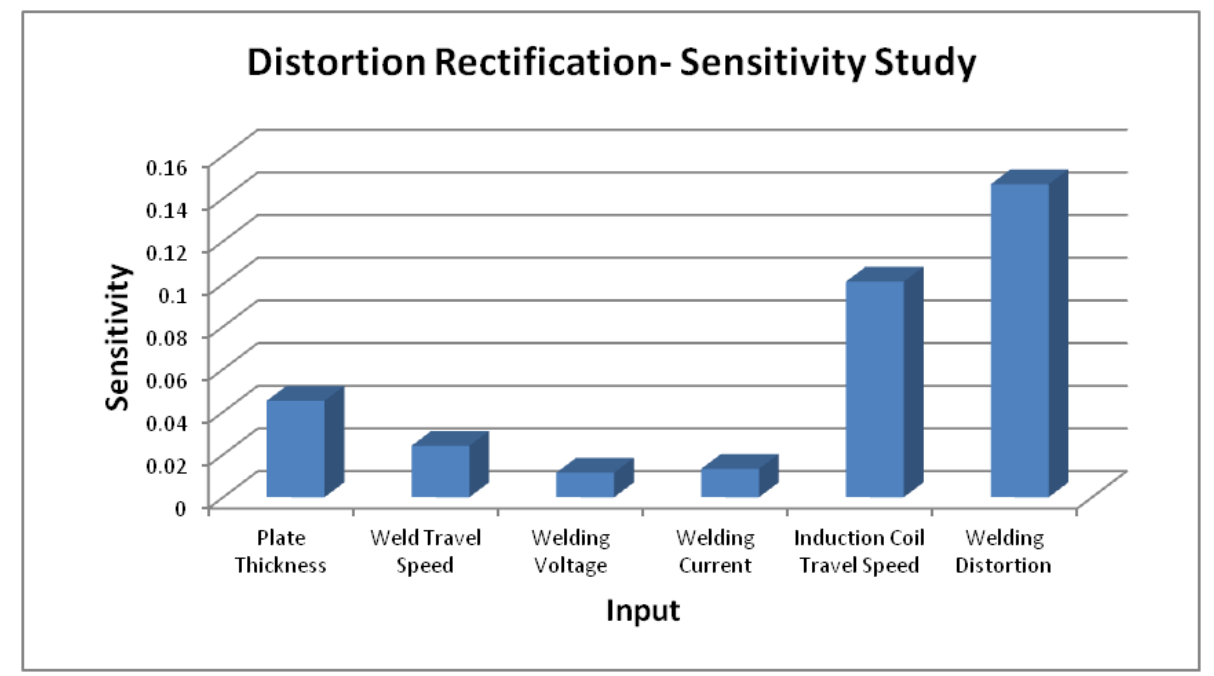

Figure 16 - Distortion Rectification Sensitivity Study (Model 2)

The sensitivity study for the second model (Figure 16) shows welding distortion to be the most dominant factor affecting the final distortion. This is to be expected as the induction heating process will produce a given level of rectification which, combined with the post weld distortion results in the residual distortion. The next most dominant factor is the travel speed of the induction coil as this directly controls the heat input to the plate from the coil. The plate thickness and welding parameters have a much lower influence than the previous two but still affect the output as they influence the geometry of the weld which will have an impact if the stiffness and conductive heat transfer of the plate in the region of the weld.

The final stage of model development was to create a model to predict the final distortion of the plate after both welding and induction heating while using all of the inputs of the previous model except the measured post weld distortion. This was conducted to create a model capable of predicting the final distortion of the plate without the need to measure the angular distortion after welding. This model was then used to predict the induction coil speed required to minimise or eliminate angular distortion. Again, the development procedure outlined earlier was followed and the model parameters producing least error during testing were as follows: 
Hidden Layers: 2

Processing Elements Layer 1: 8

Processing Elements Layer 2: 3

Momentum Coefficient:

0.7

Step Size:

0.1

Iterations:

10000

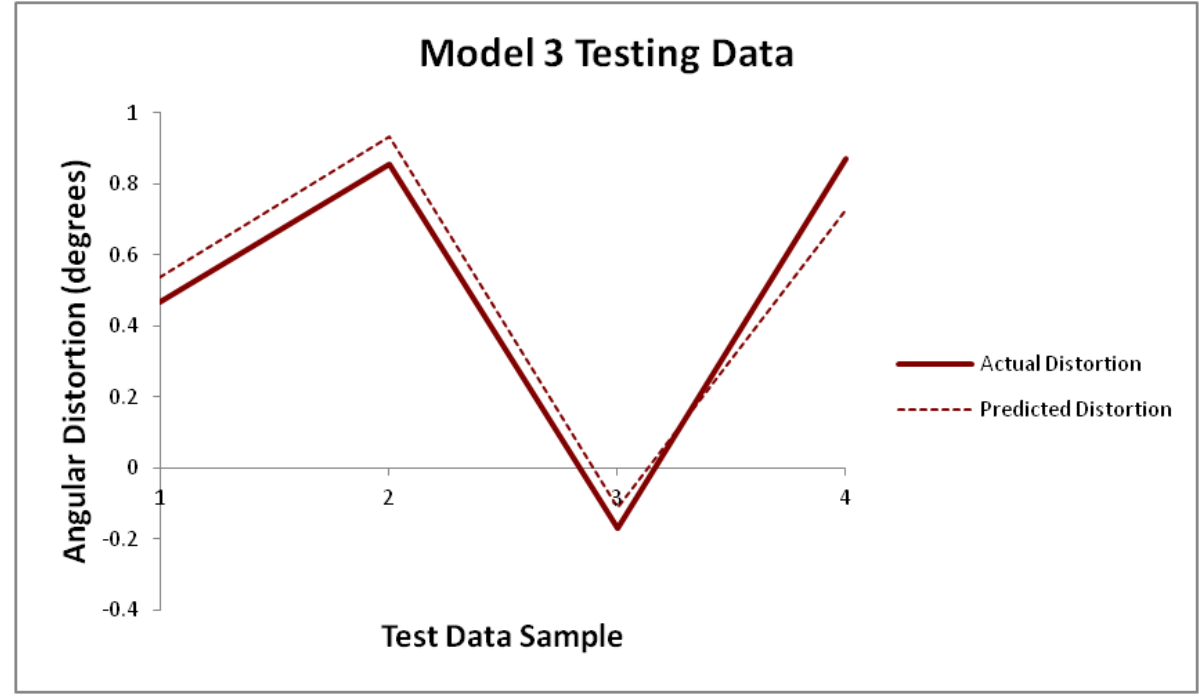

Figure 17 - Final Distortion Prediction Test Data (Model 3)

The complexity of this model falls between that of the previous two with the model comprising of 2 hidden layers of 8 and 3 processing elements respectively. The error in the testing results (Figure 17) ranges between $0.061^{\circ}$ and $0.142^{\circ}$ with a mean error of $0.087^{\circ}$. The absolute errors for this model are not significantly higher than those of the first model even with the added complexity of the model having to capture both the effects of welding and induction heating without having access to the post weld distortion value. The improved accuracy of this model over the previous model is believed to be a result of the simplified topography.

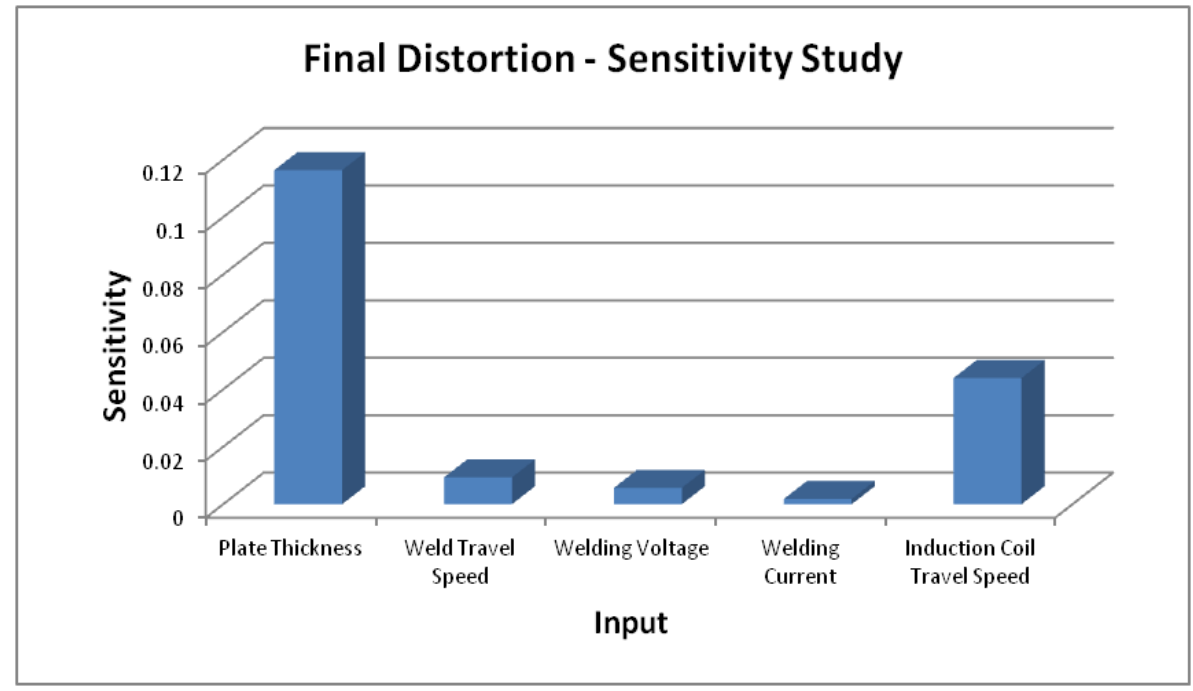

Figure 18 - Final Distortion Sensitivity Study 
Similar to the welding distortion model (Model 1), the sensitivity study for this final model (Figure 18) shows plate thickness to be the dominant factor affecting the final distortion. This is expected as this model is predicting the welding distortion within the model, and plate thickness was found to be the dominant factor affecting welding distortion in the first model. The travel speed of the induction coil was the second most dominant factor and following the results from the second model this is a logical result. As with the second model, the welding parameters have a much smaller impact on the resulting distortion of the plate after both welding and induction heating. This suggests that, for this experimental set up, the welding parameters have only a small impact on the results obtained by using the a travelling induction coil when compared to the influence of the plate thickness and induction coil travel speed.

\section{ANN Model Prediction}

To predict the induction coil travel speeds which would minimise distortion, 4 plates were welded with the same nominal welding parameters as before but the travel speeds used were $2.25 \mathrm{~mm} / \mathrm{s}$ and $2.75 \mathrm{~mm} / \mathrm{s}$. These welding travel speeds were chosen to determine whether the models were capable of predicting the respective distortion values rather than simply memorising the value for a given set of parameters. The parameters used for prediction are given in Table 1 with the final column only used as an input for model 2 . The relevant parameters were fed into the first model and predicted welding distortion values were returned for each plate. The results from this model will be discussed in the validation section.

\begin{tabular}{|r|r|r|r|r|r|}
\hline $\begin{array}{c}\text { Validation Plate } \\
\text { No. }\end{array}$ & $\begin{array}{c}\text { Plate Thickness } \\
(\mathrm{mm})\end{array}$ & $\begin{array}{c}\text { Weld Travel } \\
\text { Speed (mm/s) }\end{array}$ & $\begin{array}{c}\text { Welding } \\
\text { Voltage (V) }\end{array}$ & $\begin{array}{c}\text { Welding } \\
\text { Current (A) }\end{array}$ & $\begin{array}{c}\text { Measured Post Weld } \\
\text { Distortion (degrees) }\end{array}$ \\
\hline 1 & 6 & 2.75 & 20.7 & 214 & 0.8995 \\
\hline 2 & 8 & 2.75 & 20.7 & 221 & 1.5354 \\
\hline 3 & 8 & 2.25 & 20.6 & 222 & 1.2661 \\
\hline 4 & 10 & 2.25 & 20.6 & 218 & 1.409 \\
\hline
\end{tabular}

Table 1 - Prediction Input Data

To determine the optimum induction coil travel speed the appropriate parameters from Table 1 were used as inputs for models 2 and 3 . Along with theses parameters the induction coil travel speed was varied between $10 \mathrm{~mm} / \mathrm{s}$ and $20 \mathrm{~mm} / \mathrm{s}$ in increments of $1 \mathrm{~mm} / \mathrm{s}$ and used as an input into each model to give the predicted final distortion over this range of travels speeds. 


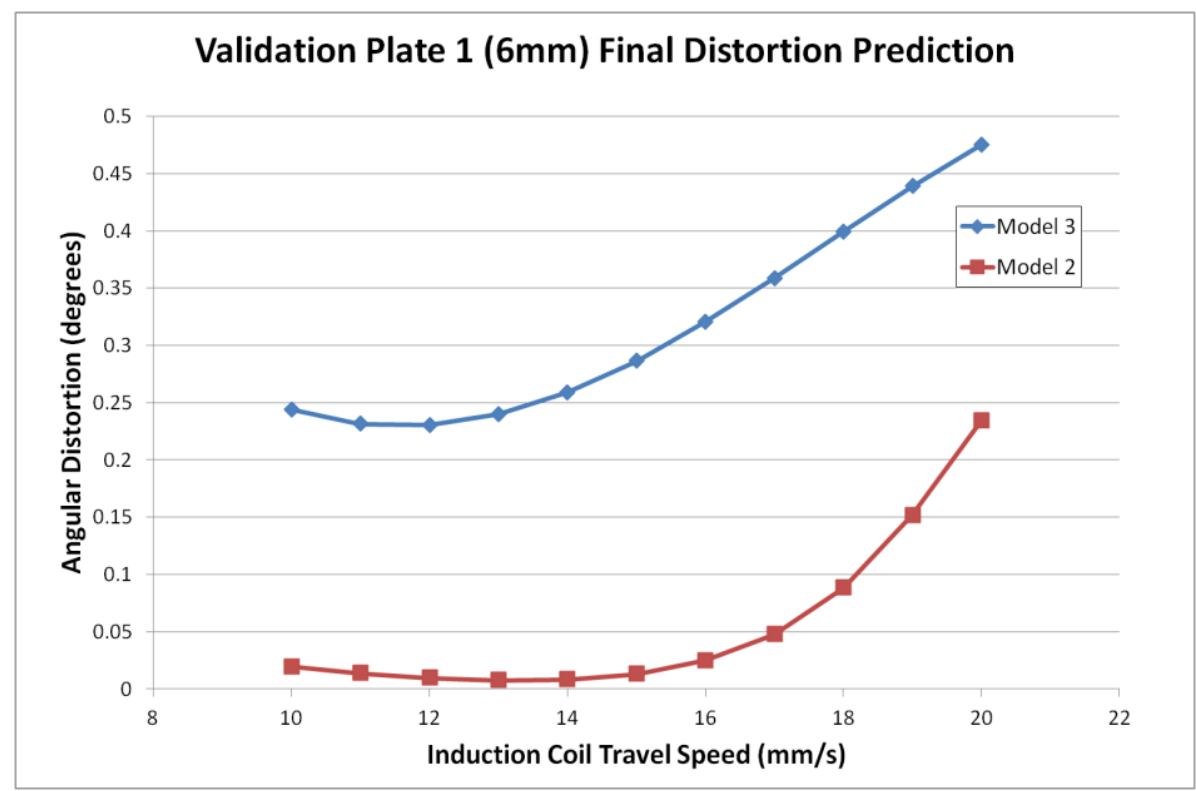

Figure 19 - Validation Plate 1 Final Distortion Prediction Showing Critical Induction Coil Travel Speed

Figure 19 shows the final distortion prediction for validation plate 1. From the plot it is evident that both model 2 and model 3 predict that there is a critical coil travel speed at which the minimum final distortion occurs. There is a difference between the models as model 2 predicts a critical speed occurring at $13 \mathrm{~mm} / \mathrm{s}$ with the final distortion effectively eliminated, while model 3 predicts a critical speed of $12 \mathrm{~mm} / \mathrm{s}$ with the minimum final distortion of $0.23^{\circ}$. For the final experimental induction heating process $13 \mathrm{~mm} / \mathrm{s}$ has been chosen as the coil travel speed.

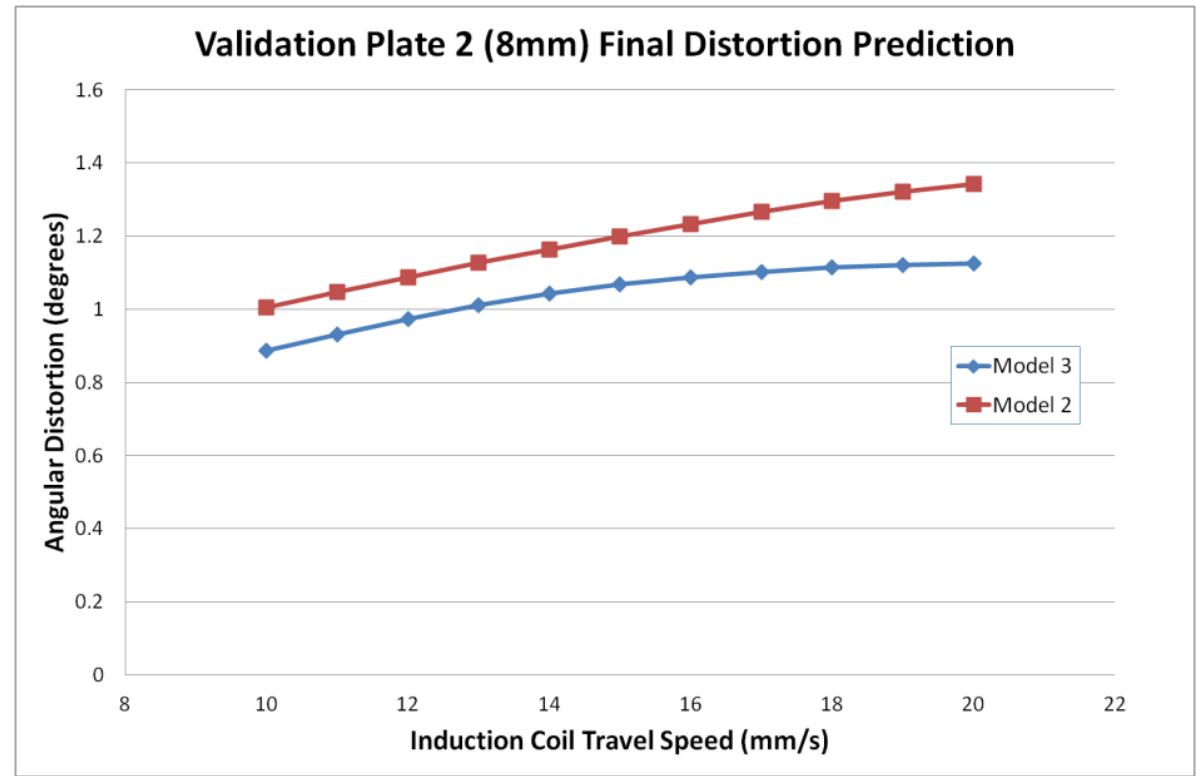

Figure 20 - Validation Plate 2 Distortion Prediction 


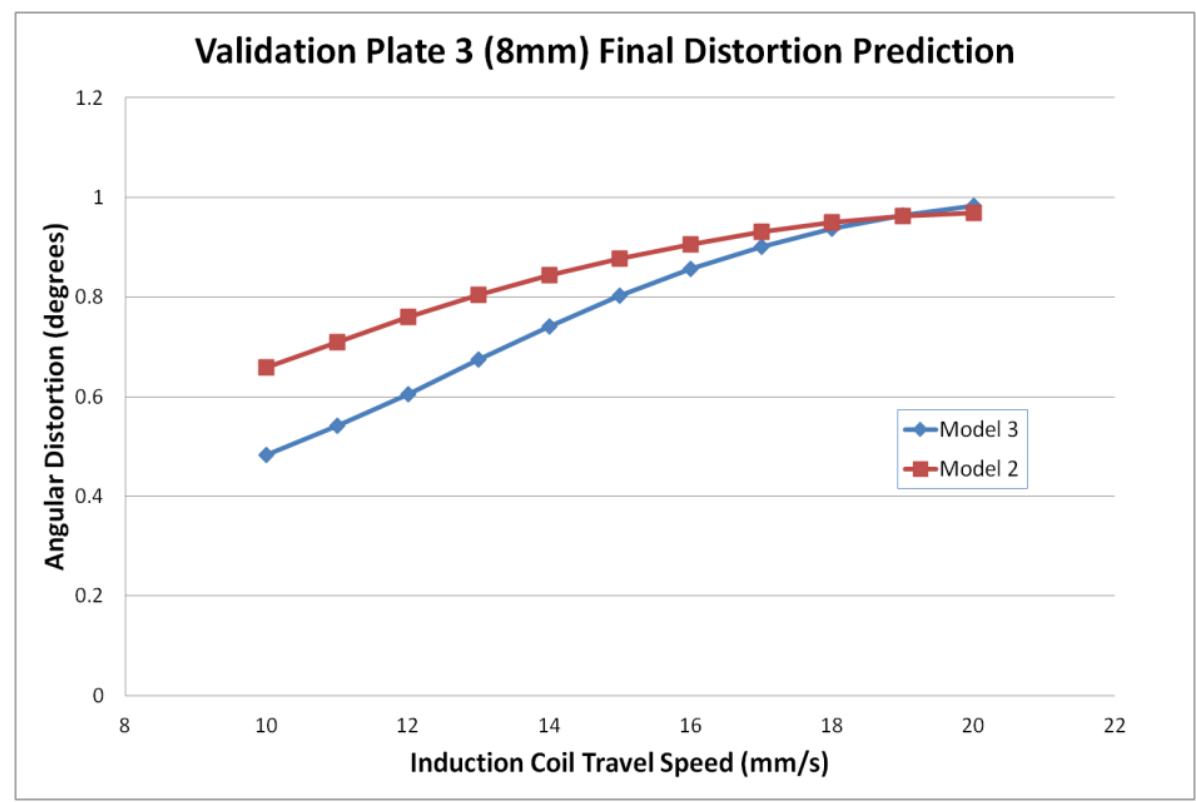

Figure 21 - Validation Plate 3 Distortion Prediction

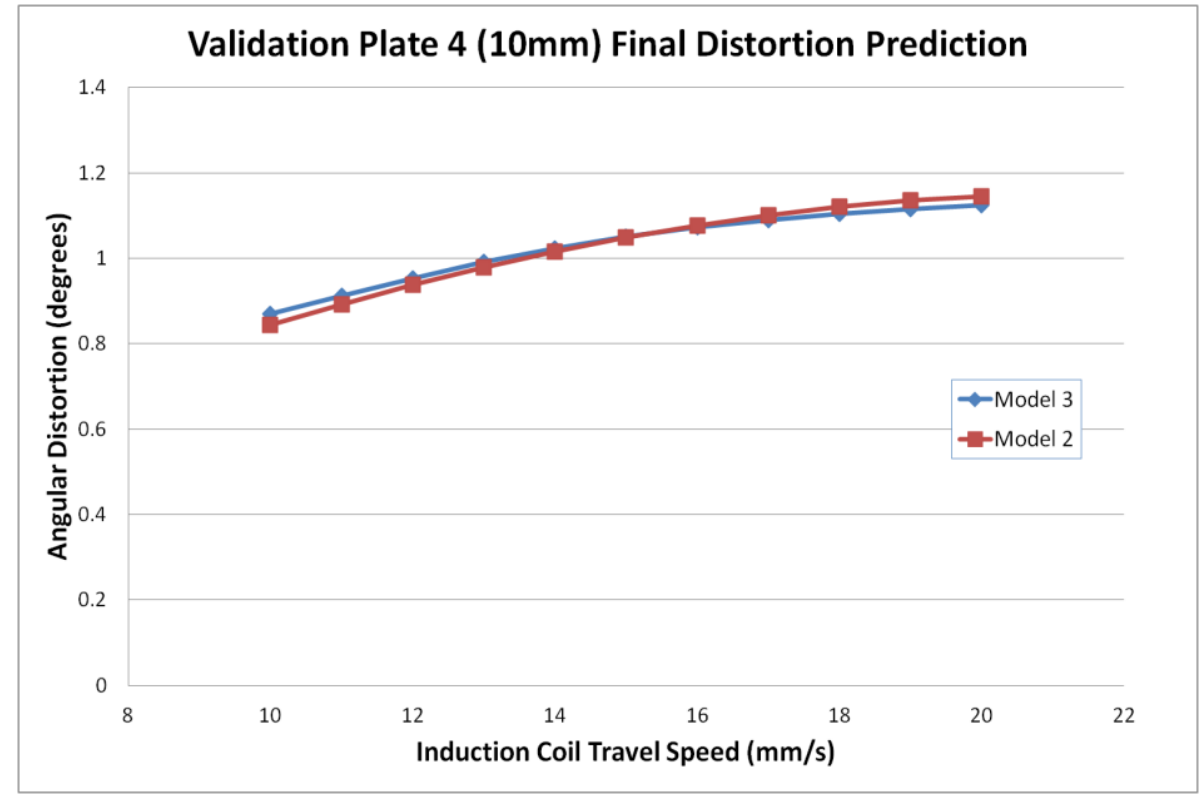

Figure 22 - Validation Plate 4 Distortion Prediction

The predicted distortion for validation plates 2, 3 and 4 (Figures 20-22) show that both models are in agreement that for these plate the minimum final distortion will occur when an induction coil travel speed of $10 \mathrm{~mm} / \mathrm{s}$ is used. Between the models there are small differences in the predicted levels of distortion for validation plates 2 and 3 , with model 2 predicting $0.12^{\circ}$ lower distortion for plate 2 and $0.17^{\circ}$ lower for plate 3 , while the predicted results for plate 4 are very similar. A coil travel speed of $10 \mathrm{~mm} / \mathrm{s}$ was chosen for the induction heating process for validation plate 2-4. 


\section{ANN Model Validation}

In order to verify the capability of each model to predict the welding distortion and final distortion, 4 plates were welded with the parameters mentioned in the previous section and the predicted results were compared to the measured welding and final angular distortion values.

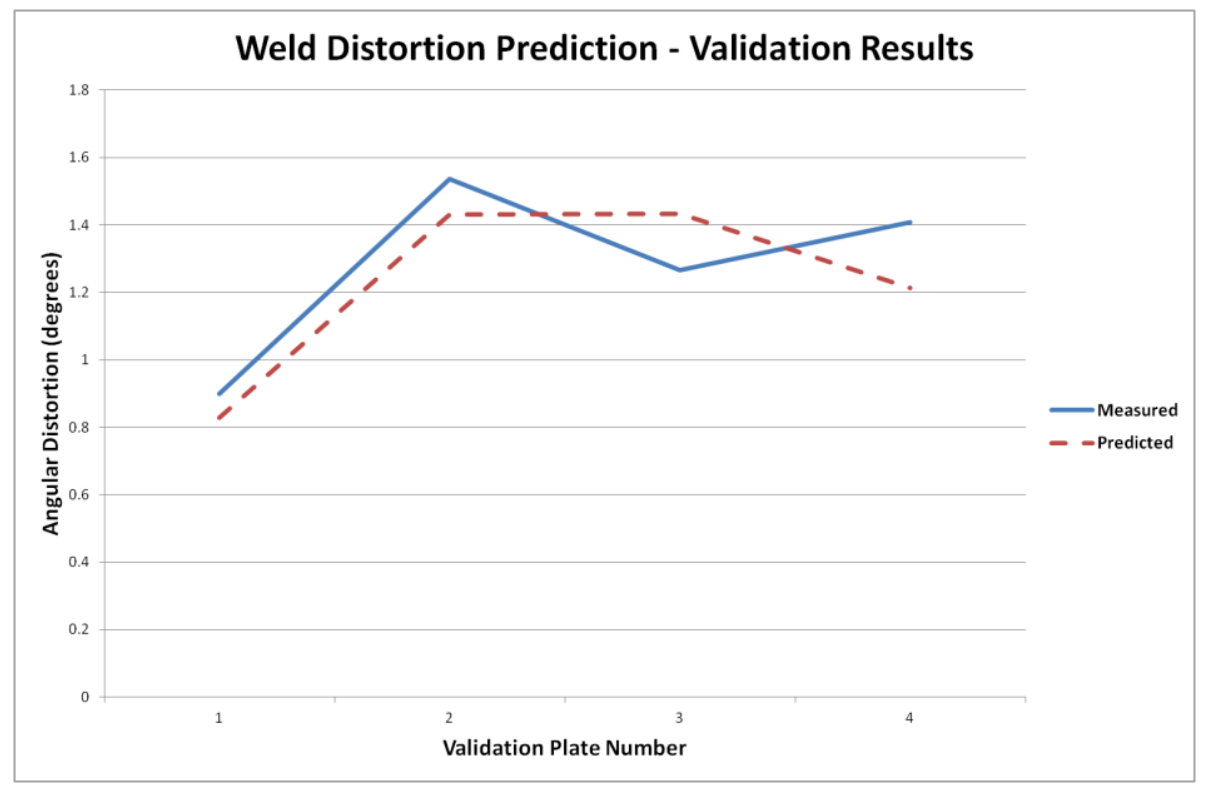

Figure 23 - Model 1 Validation Results

A comparison of the measured angular distortion and the values predicted by model 1 is given in Figure 23. The model has given values which follow the expected pattern well with only minor under and over estimations present. Average error for this model was $0.13^{\circ}$ with a maximum error of $0.19^{\circ}$. It can be seen from these results that an artificial neural network can capture the complex relationships between welding parameters and distortion and give a prediction with a relatively small error.

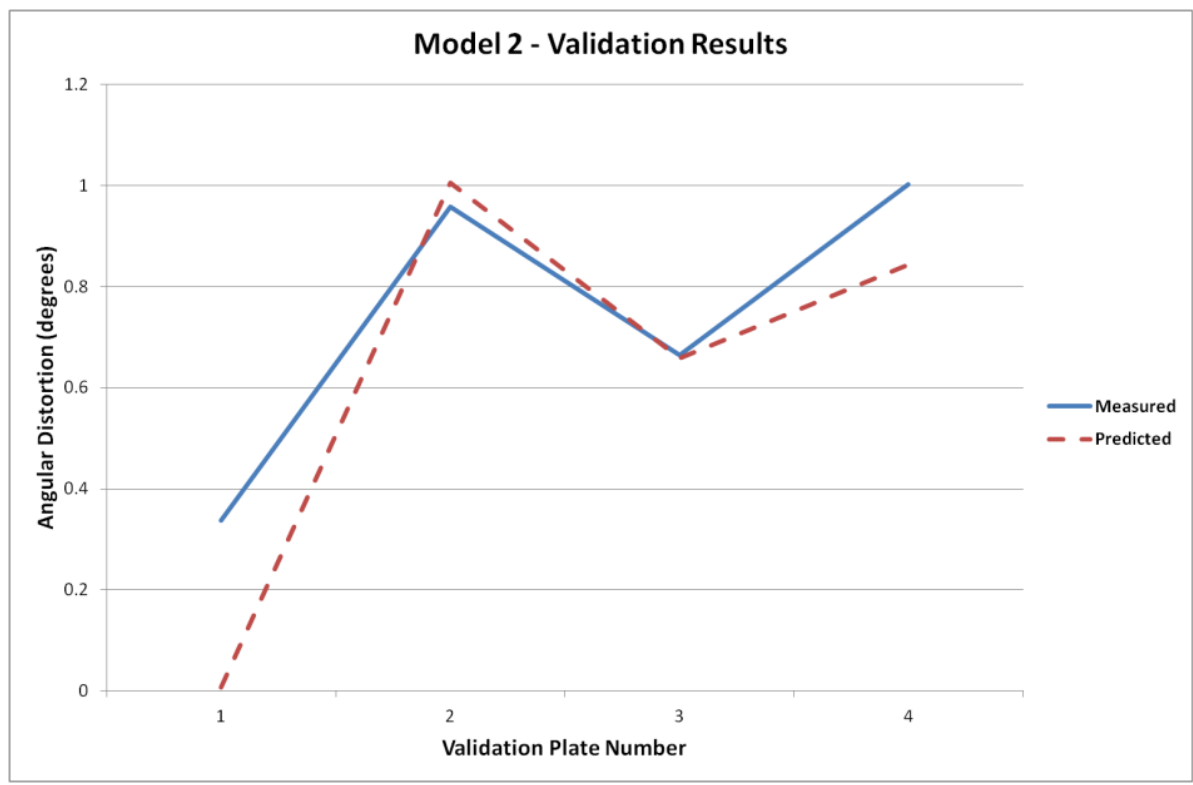

Figure 24 - Model 2 Validation Results 
The second model validation results (Figure 24) show that it underestimated the final distortion of validation plate 1 by $0.331^{\circ}$, while the error of the other results ranges from $0.006^{\circ}$ to $0.158^{\circ}$. The average error for the results is $0.136^{\circ}$ indicating that the overall accuracy of the predictions is relatively good even when taking into account the larger error in the prediction of validation plate 1. The most likely cause of this error in the $6 \mathrm{~mm}$ example is the low resolution of the training data around the critical speed. As the experimental trails to gather training data only indicated that a critical coil travel speed exists in the region of $15 \mathrm{~mm} / \mathrm{s}$, its exact position is unknown, therefore the predicted distortion rectification at $13 \mathrm{~mm} / \mathrm{s}$ is purely an estimate drawn from the data available to the model.

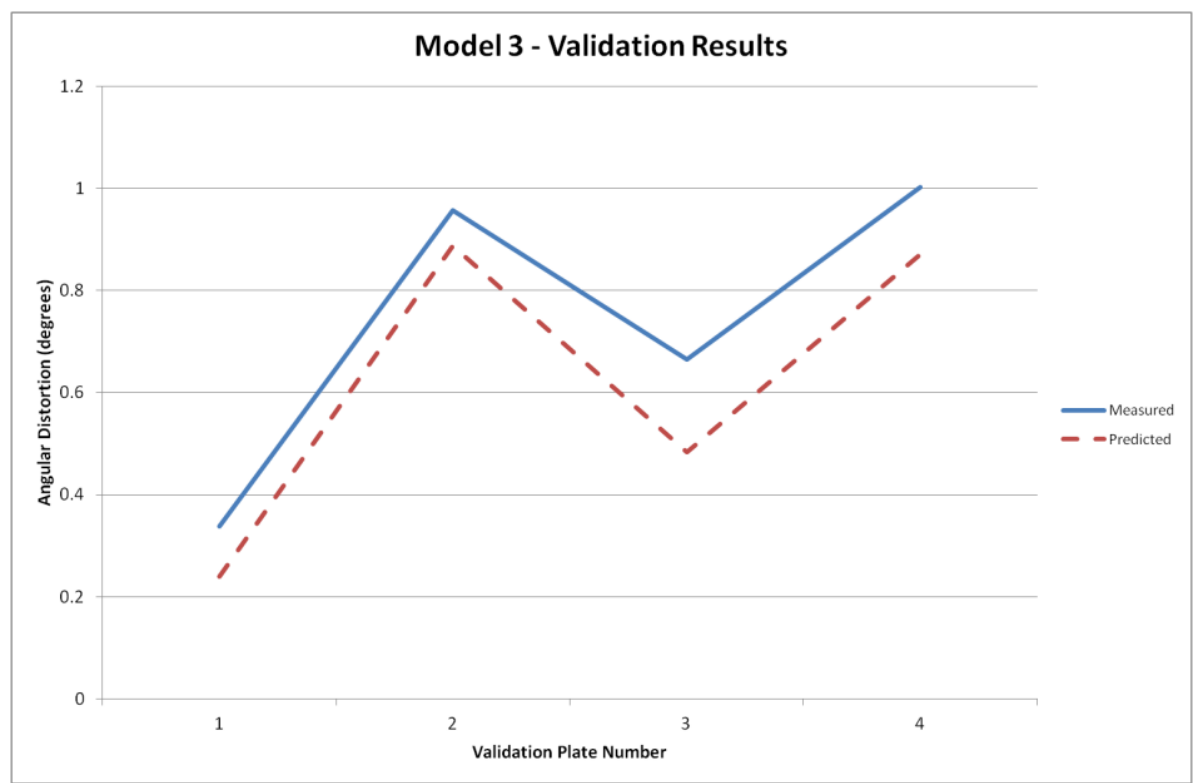

Figure 25 - Model 3 Validation Results

The results for the third model (Figure 25) show that this model has predicted the distortion of the validation plates reasonably well. In each case the predicted results have underestimated the actual values although not to a significant degree. The maximum and average errors for the validation results were $0.18^{\circ}$ and $0.12^{\circ}$ respectively which are lower than those for the second model. This leads to the conclusion that the post weld distortion can be discarded as an input to predict the final distortion as the third model does not suffer any loss in accuracy. Similarly to the second model the accuracy of this model is likely to be improved further with a larger set of training data with an increased resolution of induction coil travel speeds. 


\section{Conclusion}

The experimental trials carried out in this study have demonstrated the technique of using a travelling induction coil to rectify weld induced distortion. The results have shown the existence of a critical coil travel speed at which maximum rectification bending occurs for $6 \mathrm{~mm}$ thick plate and have shown that welding distortion can be completely rectified using this method. The experimental set up used in this trial was able to rectify up to $0.95^{\circ}$ of angular distortion for $6 \mathrm{~mm}$ plate signifying that this method may be particularly useful when dealing with steel plate $6 \mathrm{~mm}$ thick and below. This critical speed was not evident in the $8 \mathrm{~mm}$ and $10 \mathrm{~mm}$ thick plate but it is believed that by optimising the induction coil length and power input a similar pattern of results may be possible.

Artificial neural network models have been used to predict both distortion due to welding and the final distortion of steel plate after both welding and induction heating. A practical model for determining the optimum induction heating parameters to rectify welding distortion, using easily obtainable information, has been created.

The ANNs used have been shown to be capable of predicting the magnitude of welding distortion and induction heating rectification. The accuracy of prediction could be improved further with a larger set of data to train the models and an increased resolution of induction coil travel speeds to determine the exact value of the critical speed for bending would be beneficial.

The third and final model created in this study has genuine practical applications in industry when distortion reduction and rectification is of interest and with increased training data this model shows the possibility of being a robust and useful tool to systematically correct angular distortion.

\section{Acknowledgements}

The authors would like to thank Billy McGhie and BAE Systems Maritime - Naval Ships for the supply of materials and use of their facilities which made this research possible. Additional thanks are due to Mark Wells of EFD Induction Ltd and Brendan Gallagher GULLCO Ltd for their support and the provision of induction heating and track systems. 


\section{References}

1. ASM Materials Handbook Volume 6: Welding, Brazing and Soldering. p. 15.

2. McPherson,N.A. 2007. Thin Plate Distortion - The Ongoing Problem in Shipbuilding. Journal of Ship Production, Vol. 23 (2). pp. 94-117

3. Bhide, S.R., Michaleris, P., Posada, M., DeLoach, J. 2006. Comparison of buckling distortion propensity for SAW, GMAW, and FSW. Welding Journal. 85 (9) pp. 189195.

4. Camilleri, D., Comlecki, T., Gray, T.G.F. 2005. Computational prediction of out-ofplane welding distortion and experimental investigation. Journal of Strain Analysis for Engineering Design, Vol. 40 (2): pp. 161-176.

5. Leggatt, R.H. 2008. Residual Stresses in Welded Structures. International Journal of Pressure Vessels and Piping, 85: pp144-151

6. McPherson, N A. 2010. Correcting Thin Plate Distortion in Shipbuilding. Welding Journal. 89 (1): pp 30-34

7. Conrardy, C., Huang, T.D., Harwig, D., Fong, P., Kvidahl, L., Evans, N., Treaster, A. 2006.Practical Welding Techniques to Minimise Distortion in Lightweight Ship Structures. Journal of Ship Production, 22: pp. 239-247.

8. Campbell, S.W., Galloway, A.M. and McPherson, N.A. 2011. Techno-Economic Evaluation of Reducing Shielding Gas Consumption in GMAW whilst Maintaining Weld Quality. International Journal of Advance Manufacturing Technology. 225 (10). pp. 1863-1872

9. Long, H., Gery, D. Carlier, A., Maropoulos, P.G. 2009. Prediction of Welding Distortion in Butt Joint of Thin Plates. Materials and Design, 30: pp 4126-4135

10. Campbell, S.W., Galloway, A.M. and McPherson, N.A. 2011. Techno-Economic Evaluation on the Effects of Alternating Shielding Gases for Advanced Joining Processes. Proceedings of the Institution of Mechanical Engineers, Part B: Journal of Engineering Manufacture, 225 (10). pp. 1863-1872

11. Lightfoot, M.P., Bruce, G.J., McPherson, N.A., Woods, K. 2005. The Application of Artificial Neural Networks to Weld-Induced Deformation in Ship Plate, Welding Journal, 84 (2) pp. 23-30

12. Lightfoot, M.P., McPherson, N.A., Woods, K., Bruce, G.J. 2006. Artificial Neural Networks as an Aid to Steel Plate Distortion Reduction, Journal of Materials Processing Technology, 172 (2): pp. 238-242

13. Pattee, H.E., Evans, R.M, Monroe, R.E. 1970. Effect of Flame and Mechanical Straightening on Material Properties of Weldments, Summary Report to the Ship Structure Committee, Project SR-185 Straightening Distorted Weldments

14. McPherson, N.A., Coyle, A., Wells, M. 2008. Induction Heat Straightening - A Distortion Rework Reduction Tool for Thin Plate. Welding and Cutting, 7 (3): pp. 162166 
15. Lee, J.H., Lee, K., Yun, J.S. 2006. An Electromagnetic and Thermo-Mechanical Analysis of High Frequency Induction Heating for Steel Plate Bending. Key Engineering Materials, Vols. 326-328: pp. 1283-1286

16. Sadeghipour, K., Dopkin, J.A., Li, K. 1996. A Computer Aided Finite Element/ Experimental Analysis of Induction Heating Process of Steel, Computers in Industry, 28: pp. 195-205

17. Bae, K.L, Yang, Y.S, Hyun, C.M., Cho, S.H. 2008. Derivation of Simplified Formulas to Predict Deformations of Plate in Steel Forming Process with Induction Heating, International Journal of Machine Tools and Manufacture, 48: pp. 1646-1652

18. Ngyuyen, T.T., Yang, Y.S., Bae, K.Y., Choi, S.N. 2009. Prediction of Deformations of Steel Plate by Artificial Neural Network in Forming Process with Induction Heating, Journal of Material Science and Technology, 23: pp. 1211-1221

19. Thumati, B.T. and Sarangapani, J. 2009 Estimation and Control of Nonlinear Discrete-time Systems, In Wen Yu (Ed), Recent Advances in Intelligent Control Systems $1^{\text {st }}$ ed., pp. 89-123 (Springer, London)

20. Campbell, S.W., Galloway, A.M., McPherson, N.A. Techno-Economic Evaluation of Reducing Shielding Gas Consumption in GMAW whilst Maintaining Weld Quality. International Journal of Advanced Manufacturing Technology, In Press. DOI: 10.1007/s00170-012-3961-2 


\begin{tabular}{|c|c|c|c|c|c|}
\hline $\begin{array}{l}\text { Plate } \\
\text { no. }\end{array}$ & $\begin{array}{c}\text { Base Plate } \\
\text { Thickness (mm) }\end{array}$ & $\begin{array}{l}\text { Weld Travel Speed } \\
\qquad(\mathrm{mm} / \mathrm{s})\end{array}$ & $\begin{array}{l}\text { Average Measured } \\
\text { Weld Voltage (V) }\end{array}$ & $\begin{array}{c}\text { Average Measured } \\
\text { Weld Current (A) }\end{array}$ & $\begin{array}{c}\text { Induction Coil } \\
\text { Travel Speed } \\
\text { (mm/s) }\end{array}$ \\
\hline 1 & 6 & 3 & 20.5 & 206 & 10 \\
\hline 2 & 6 & 3 & 20.5 & 210 & 15 \\
\hline 3 & 6 & 3 & 20.5 & 211 & 20 \\
\hline 4 & 6 & 3 & 20.6 & 208 & 25 \\
\hline 5 & 6 & 2.5 & 20.6 & 210 & 10 \\
\hline 6 & 6 & 2.5 & 20.5 & 216 & 15 \\
\hline 7 & 6 & 2.5 & 20.5 & 214 & 20 \\
\hline 8 & 6 & 2.5 & 20.6 & 217 & 25 \\
\hline 9 & 6 & 2.5 & 20.6 & 212 & 30 \\
\hline 10 & 6 & 2 & 20.5 & 219 & 10 \\
\hline 11 & 6 & 2 & 20.5 & 209 & 15 \\
\hline 12 & 6 & 2 & 20.5 & 213 & 20 \\
\hline 13 & 6 & 2 & 20.5 & 214 & 25 \\
\hline 14 & 6 & 2 & 20.6 & 217 & 30 \\
\hline 15 & 8 & 3 & 20.5 & 209 & 10 \\
\hline 16 & 8 & 3 & 20.6 & 210 & 15 \\
\hline 17 & 8 & 3 & 20.5 & 209 & 20 \\
\hline 18 & 8 & 3 & 20.5 & 216 & 25 \\
\hline 19 & 8 & 3 & 20.5 & 208 & 30 \\
\hline 20 & 8 & 2.5 & 20.4 & 213 & 10 \\
\hline 21 & 8 & 2.5 & 20.6 & 216 & 15 \\
\hline 22 & 8 & 2.5 & 20.5 & 213 & 20 \\
\hline 23 & 8 & 2.5 & 20.5 & 209 & 25 \\
\hline 24 & 8 & 2.5 & 20.4 & 213 & 30 \\
\hline 25 & 8 & 2 & 20.5 & 209 & 10 \\
\hline 26 & 8 & 2 & 20.7 & 211 & 15 \\
\hline 27 & 8 & 2 & 20.7 & 219 & 20 \\
\hline 28 & 8 & 2 & 20.7 & 208 & 25 \\
\hline 29 & 8 & 2 & 20.6 & 212 & 30 \\
\hline 30 & 10 & 3 & 20.7 & 207 & 10 \\
\hline 31 & 10 & 3 & 20.6 & 208 & 15 \\
\hline 32 & 10 & 3 & 20.6 & 209 & 20 \\
\hline 33 & 10 & 3 & 20.8 & 215 & 25 \\
\hline 34 & 10 & 3 & 20.6 & 205 & 30 \\
\hline 35 & 10 & 2.5 & 20.7 & 206 & 10 \\
\hline 36 & 10 & 2.5 & 20.7 & 207 & 15 \\
\hline 37 & 10 & 2.5 & 20.7 & 210 & 20 \\
\hline
\end{tabular}




\begin{tabular}{|r|r|r|r|r|r|}
38 & 10 & 2.5 & 20.8 & 214 & 25 \\
\hline 39 & 10 & 2.5 & 20.7 & 214 & 30 \\
\hline 40 & 10 & 2 & 20.6 & 220 & 10 \\
\hline 41 & 10 & 2 & 20.6 & 216 & 15 \\
\hline 42 & 10 & 2 & 20.6 & 211 & 20 \\
\hline 43 & 10 & 2 & 20.7 & 212 & 25 \\
\hline 44 & 10 & 2 & 20.5 & 214 & 30 \\
\hline
\end{tabular}

Table 2 - Experimental Data 